\title{
Teaching with Primary Sources: Looking at the Support Needs of Instructors
}

\author{
Kurtis Tanaka
}

\begin{tabular}{|c|c|c|}
\hline Daniel Abosso & Diana Dill & Emily Kader \\
\hline Krystal Appiah & Carrie Donovan & Jessica Keyes \\
\hline Katie Atkins & Lori DuBois & Paula Kiser \\
\hline Peter Barr & Lisa Duncan & Joel D. Kitchens \\
\hline Arantza Barrutia- & Sarah Evelyn & Maggie Kopp \\
\hline Wood & Mary Feeney & Andrew Laas \\
\hline Shatha Baydoun & Patricia Figueroa & Bill Landis \\
\hline Catherine Bazela & Rebecca Friedman & Christina Larson \\
\hline Cara Bertram & Myranda Fuentes & David Lewis \\
\hline Colleen Boff & Danielle Gabbard & Sara Logue \\
\hline Steve Borrelli & Eleonora Gandolfi & Maureen Maryanski \\
\hline Jay-Marie Bravent & Chloe Gerson & Jennifer Meehan \\
\hline Sarah Brennan & Kelly Godfrey & Ruthann Miller \\
\hline Tina Budzise-Weaver & Melissa Grafe & Rebecca Miller Waltz \\
\hline Margaret Burri & Brenda Gunn & Meg Miner \\
\hline Liz Cheney & Jeanann Haas & Sarah Morris \\
\hline Cait Coker & Terese Heidenwolf & Kevin M. O’Sullivan \\
\hline Heather Cole & Heidi Herr & Catherine Oliver \\
\hline Lisa Conathan & Laura Hibbler & Barbara Olson \\
\hline Emily Cook & Matthew J. K. Hill & Anne Peale \\
\hline Danielle Cooper & David Hirsch & Matt Phillips \\
\hline Joshua Dacey & Stefanie Hunker & Roxane Pickens \\
\hline J. Gordon Daines III & Jamie Johnson & Julie Porterfield \\
\hline
\end{tabular}

Sara Powell

Marcus Robyns

Dylan Ruediger

Deirdre Scaggs

Carrie Schwier

Matthew Sheehy

Nicole Shibata

Dainan M. Skeem

Holly Snyder

Linda Stepp

Matthew Strandmark

Morgan Swan

Michelle Sweetser

Gabriel Swift

Jason Tomberlin

Niamh Wallace

Berenika Webster

Ashley Werlinich

Clare Withers

Lijuan Xu 


\section{ITHAKA S+R}

Ithaka $\mathrm{S}+\mathrm{R}$ provides research and strategic guidance to help the academic and cultural communities serve the public good and navigate economic, demographic, and technological change. Ithaka S+R is part of ITHAKA, a not-for-profit organization that works to advance and preserve knowledge and to improve teaching and learning through the use of digital technologies. Artstor, JSTOR, and Portico are also part of ITHAKA.

Copyright 2021 ITHAKA. This work is licensed under a Creative Commons Attribution 4.0 International License. To view a copy of the license, please see https://creativecommons.org/licenses/by/4.0/.

ITHAKA is interested in disseminating this brief as widely as possible. Please contact us with any questions about using the report: research@ithaka.org.

We would like to thank ProQuest for its support of this research.

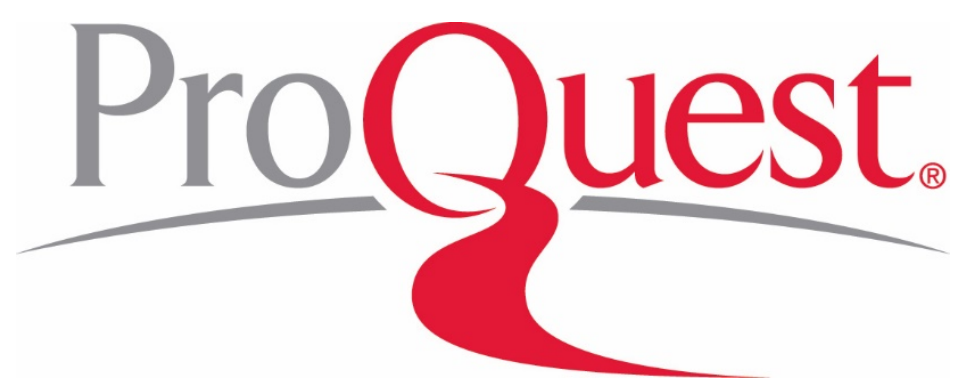




\section{Table of Contents}

Executive Summary __ 3

Introduction _ 4

Methods 6

Defining Teaching with Primary Sources __ 8

How Instructors Discover Primary Sources __ 9

Teaching to Your Strengths: The Role of Research in Discovery __ 10

Looking at Home: Discovery in Institutional Collections __ 11

Looking Beyond Institutional Collections __ 13

Discovering Primary Sources: Present and Future___ 16

Student Discovery __ 17

Digital Resources and Databases___ 17

Physical Collections _ 20

Balancing Curation and Open Discovery __ 21

Pedagogy and Course Design ___ 23

"You Should Just Know": Learning to Teach with Primary Sources __ 23

Course Design: Teaching with Primary Sources in Large Classes _ 25

Course Design: Teaching with Primary Sources in Smaller Courses___ 28

Course Design: Textbooks and Primary Sources___ 30

Course Design: Conclusions___ 33

In the Archives_On the Screen: Teaching and Learning with Primary Sources __ 34

Enchanting and Demystifying: Engaging Students with Primary Sources ___ 34

Engaging with Primary Sources: Working with Physical Collections ___ 36

Engaging with Primary Sources: Decoding Content____ 38

Engaging with Primary Sources: Digitized and Digital Materials __ 40

Conclusions _ 44

Teaching Students to Fish _ 44

Physical versus Digital or Physical and Digital? __ 45

Collaboration 446

Teaching with Primary Sources: Post-COVID Futures___ 46

Recommendations _ 48

Working with Collections 448

Outreach and Collaboration $\quad 49$

Curriculum and Course Development__ 50

Appendix 1: Teams and Local Reports __ 52

Appendix 2: Supporting Teaching with Primary Sources Interview Guide __ 56 


\section{Executive Summary}

Ithaka S+R's Teaching Support Services Program investigates the teaching practices and support needs of collegiate instructors. Our most recent project in this program, "Supporting Teaching with Primary Sources," focused on identifying how to effectively support instructors and their students find, access, and use primary sources in classroom environments.

Encounters with primary sources-historical or contemporary artifacts that bear direct witness to a specific period or event-are central to the pedagogy of many disciplines, especially in the humanities and humanistic social sciences. Their use in undergraduate instruction aligns with universities' commitments to experiential and inquiry-based learning and library initiatives focused on media and information literacy. Reflecting the importance of the topic within higher education, "Supporting Teaching with Primary Sources" attracted the largest cohort of any Ithaka S+R program to date. Research teams at 26 academic libraries in the United States and United Kingdom joined the program. ProQuest, which sponsored the project, conducted interviews with instructors at an additional 16 universities. Together, the 27 research teams interviewed 335 instructors, asking detailed questions about how instructors design courses and assignments utilizing primary sources, and where and how instructors and their students discover and access primary sources appropriate for classroom use.

These transcripts yielded rich data about how stakeholders-including university libraries, faculty, administrators, publishers, and professional organizations-can best support undergraduate instruction using primary sources. Detailed findings and actionable recommendations can be found in the body of this report. Our findings and recommendations are grouped around the following important challenges and emerging best practices:

- Identifying appropriate primary sources. While digitization has made a wide variety of primary sources available to instructors, discovery tools are rarely optimized to make it easy for instructors to locate resources appropriate for classroom use.

- Students' skills at discovering and evaluating primary sources. Students often lack familiarity with relevant search tools and strategies to discover sources and struggle to evaluate the value of the sources they do find. Maximizing student learning requires instruction in both the technical knowledge of discovery and information literacy.

- Integrating primary sources requires careful course design. Effective pedagogy often involves scaffolding exposure to primary sources both within courses and across curricula, but many instructors default towards proscribing which sources students use, especially in large introductory classes.

- Students benefit from exposure to both physical and digital sources. Physical encounters with material sources are highly-valued by instructors for inspiring student curiosity, but digital sources expand student access and the depth of library collections.

- Collaboration pays dividends. Teaching effectively with primary sources requires many forms of knowledge and expertise. Long-term relationships between instructors, librarians, archivists, and museum staff are particularly likely to lead to the scaffolded exposure to primary sources that seems best suited to optimal student learning outcomes. 


\section{Introduction}

Primary sources are unique pedagogical tools that drive curiosity, engagement, even awe in students, and allow instructors to achieve their student learning goals, advancing the educational mission of their college or university. Because primary sources are typically under the stewardship of archivists, special collections librarians, or museum professionals (at least in the case of physical materials), the pedagogical practices surrounding their use are often deeply collaborative, and allow academic libraries, archives, and museums to provide a unique value proposition to their instructors and institutions. Conversely, the ever-growing amount of materials made digitally available by universities (especially in response to the COVID-19 pandemic) and third parties continues to open up new possibilities in the classroom and for new approaches to teaching with primary sources to emerge. Collections themselves are also undergoing transformations, as new research and teaching priorities continue to press for more diverse representation in collections and new methods for recovering the voices of the historically silenced and marginalized. This report aims to shed light on how these trends intersect with actual pedagogical practice. It captures how instructors utilize primary sources in their teaching, the challenges and needs they have in doing this effectively, and provides a basis for how libraries, archives, museums, and third parties can respond to better meet these evolving needs.

Over the past six years, Ithaka $\mathrm{S}+\mathrm{R}$ has fielded numerous projects to help the higher education sector, and especially academic libraries, better support not only current but also emerging research practices, more recently extending our cohort-based methodology to examine instructional support. The first Teaching Support Services project, focusing on instruction in business education, concluded last year. Here we present the findings from the second project in the series on supporting teaching with primary sources. While a part of the Support Services series, this project also represents a departure, for in this case the project was framed not around a specific discipline or field, but rather a kind of pedagogical practice. While it is true that certain disciplines rely more heavily on primary source materials (see "Methods" for our working definition) in their instruction than others, by focusing on overarching pedagogical approaches rather than manifestations in a specific subject area, this project aimed to highlight the challenges, successes, and opportunities for instructors teaching with primary sources across the breadth of the academy. A focus on practice rather than subject also allows libraries, archives, and special collections to capitalize on their central positions on campus, reaching across disciplinary silos and strengthening their services where there is the greatest need and the potential for the greatest impact.

The use of primary source materials for both research and instruction is also a topic of special interest for the library and archives communities and therefore reaches across both the Association of College and Research Libraries (ACRL) as well as the Society for American Archivists (SAA). In 2018, SAA and ACRL, through its Rare Books and Manuscripts Section (RBMS), issued the "Guidelines for Primary Source Literacy," to provide a framework for the use of primary sources to develop critical literacies and assessment strategies, facilitate 
instructor/librarian/archivist discussions, and enhance programming. ${ }^{1}$ The "Guidelines" can be seen as an effort to operationalize ACRL's more general "Framework for Information Literacy for Higher Education,"2 though, as the authors of the "Guidelines" note, primary sources can also teach other literacies, such as visual literacy, as well as concepts such as collective memory and cultural heritage. Likewise, "archival literacy" is a related, more specific framework pertaining to working with primary sources specifically in the context of the archive. In addition to the guidelines and frameworks, there exists a robust literature relating to teaching with primary sources covering an extensive range of topics and approaches. ${ }^{3}$

Clearly, primary sources constitute a locus of intense and vibrant activity in the profession, even more so in the wake of the COVID-19 pandemic. The Teaching with Primary Sources Collective (TPS Collective), for example, has hosted numerous community calls and workshops following this shift to remote learning in Spring 2020 and hosted an "unconference" around the annual meeting of the SAA. 4 The breadth of potential pedagogical outcomes as well as the high level of professional development work being done around primary sources makes them an especially productive avenue for exploration, and, by connecting them to instructor practices and goals, a wellspring for collaboration and innovation. This is all the more critical, as is discussed in the findings, because instructors see archivists, special collections librarians, and museum staff (hereafter, "collections staff") as experts in primary source pedagogy, and of course, as experts in the materials under their care, and so often look to them for guidance. 5

The need for both collaboration and innovation in the use of primary sources as pedagogical tools has taken on increased urgency as a result of the COVID-19 pandemic. As colleges and universities closed their campuses and transitioned to remote learning in the spring 2020 semester, special collections and archives were likewise forced to close their doors, prompting, if not an existential crisis, at least a crisis of relevance. An embodied encounter with physical objects is widely seen as an invaluable experience for students, and a crucial element of primary source pedagogy, especially when framed around teaching with the institution's own collections. The shift to remote instruction rendered such engagements unfeasible, and necessitated a reliance on digital or digitized resources and modalities. The tensions surrounding physical as opposed to digital resources is nothing new, however, and while the research for this project was

\footnotetext{
1 "Guidelines for Primary Source Literacy," the ACRL RBMS-SAA Joint Task Force on the Development of Guidelines for Primary Source Literacy, February 12, 2018, https://acrl.ala.org/acrlinsider/archives/15473.

2 "Framework for Information Literacy for Higher Education," American Library Association, February 9, 2015, http://www.ala.org/acrl/standards/ilframework.

${ }^{3}$ See "Guidelines" for a select, annotated bibliography, as well as a more extensive bibliography generated by the TPS Collective: https://tpscollective.org/bibliographyl. See also this series of case studies on teaching with primary sources published by SAA: https://www2.archivists.org/publications/epubs/Case-Studies-Teaching-With-Primary-Sources.

${ }^{4}$ For more information about the TPS collective visit their website at: https://tpscollective.org/.

${ }^{5}$ For considerations of the pedagogical value of primary sources see P. Garcia, J. Lueck and Elizabeth Yakel, "The Pedagogical Promise of Primary Sources: Research Trends, Persistent Gaps, and New Directions," The Journal of Academic Librarianship 45 (2019): 94-101; W. Hayden, "And Gladly Teach: The Archival Turn's Pedagogical Turn," College English 80 (Nov. 2017): 133-58; D. Pace, "The Amateur in the Operating Room: History and the Scholarship of Teaching and Learning," The American Historical Review 109 (Oct. 2004); Marcus C. Robyns, "The Archivist as Educator: Integrating Critical Thinking Skills into Historical Research Methods Instruction," The American Archivist 64:2 (Fall-Winter 2001): 371-73; Barbara Rockenbach, "Archives, Undergraduates, and Inquiry-Based Learning: Case Studies from Yale University Library," The American Archivist 74:1 (Spring/Summer 2011): 297311.
} 
conducted prior to the pandemic, the themes of format and delivery were already central. Crucially, the urgency of the pandemic sheds new light on this ongoing problem, with our findings emphasizing gaps in digital pedagogy with primary sources that will be a priority for the field in the years to come. We therefore pay close attention to issues surrounding format in the findings in order to highlight instructor viewpoints on the pedagogical utility of different kinds of resources as well as to provide a benchmark for how these views may shift as a result of the pandemic, including through a forthcoming study by Ithaka S+R. ${ }^{6}$

While format is undeniably a pressing issue, this report explores the entirety of instructors' engagement with primary sources, from their pedagogical training through their discovery, access, and use of primary sources in their classrooms. By focusing on practice rather than subject area, we highlight the common challenges instructors face across a variety of academic fields as well as their perceptions of key issues facing them and their students. 7 We share our findings and recommendations in order to highlight the areas where there is greatest opportunity to meaningfully support undergraduate instruction.

\section{Methods}

This project is a part of Ithaka $\mathrm{S}+\mathrm{R}$ 's ongoing program to conduct research on the information practices of instructors in collaboration with higher education institutions. Participation in the project was open to any institution of higher learning able to conform to the project specifications, such as timeline and research capacity. This project represents Ithaka S+R's largest collaboration to date, with 26 institutions (listed in Appendix 1) joining the project, a testament to the concerted interest the library community holds in the use of primary sources for instruction. ProQuest, which provided sponsorship support that defrayed project participation fees for the institutional partners, fielded an additional team and conducted interviews with instructors across a variety of institutions in the United States and United Kingdom.

Each participating institution fielded its own local research team consisting of between one and four members, and mostly included special collections librarians and archivists, though other roles, such as liaison librarians, were also represented on the teams. Following a training workshop designed and led by Danielle Cooper, each team conducted approximately 15 semistructured interviews with instructors on their own campuses following an interview guide designed by Ithaka S+R (See Appendix 2 for Interview Guide). While recognizing that archivists, special collections librarians, and museum staff provide significant instruction with primary sources, the project prioritized interviewing instructors who were the instructors of record for their course. Each local team conducted their own analysis of the data they collected in their

\footnotetext{
${ }^{6}$ See project announcement: Danielle Cooper, Liam Sweeney, and Kurtis Tanaka, "Teaching with Cultural Heritage Online During the Pandemic: New Mellon-Funded Project, August 17, 2020, https://sr.ithaka.org/blog/teaching-with-cultural-heritage-online-duringthe-pandemicl.

${ }^{7}$ Many of these challenges are complex and longstanding. A 2007-08 survey on the use of primary sources in undergraduate history courses show many instructors struggling with remarkably similar issues around discovery, access, and effective pedagogy. Doris J. Malkmus, "Teaching History to Undergraduates with Primary Sources: Survey of Current Practices," Archival Issues 31:1 (2007): 2582.
} 
interviews and composed their own, institution specific report. Teams had the option of keeping their report internal or to make the report publicly available through their institutional repositories. These reports provide a complement to this capstone report and links to them can be found in Appendix 1.

\section{Figure 1a}

\begin{tabular}{lc} 
Rank & Percent \\
\hline Lecturer/Adjunct/Postdoc/Graduate Student & 19 \\
Assistant Professor & 21 \\
Associate Professor & 32 \\
Professor & 28 \\
Total & $\mathbf{1 0 0}$ \\
\hline
\end{tabular}

\section{Figure 1b}

\begin{tabular}{ll} 
Department & Percent \\
\hline Academic Center/Library & 1 \\
African and African American Studies & 2 \\
\hline American Studies & 2 \\
\hline Anthropology and Sociology & 4 \\
\hline Art, Architecture, Art History, and Design & 8 \\
\hline Classics/Scripture & 3 \\
\hline Earth, Environmental, and Geography & 1 \\
\hline Education & 1 \\
\hline English & 18 \\
\hline Government \& Law & 3 \\
\hline History & 30 \\
\hline Journalism, Media, and Communication & 3 \\
\hline Modern Languages and Literatures & 7 \\
\hline Music, Dance, Theater, Performance Studies & 4 \\
\hline Other - Interdisciplinary & 4 \\
\hline Philosophy/Religion & 5 \\
\hline Women's, Gender and Sexuality Studies & 3 \\
\hline Total & 3 \\
\hline
\end{tabular}


Ithaka S+R collected 335 anonymized transcripts from the 27 teams participating in the project. We selected 50 transcripts as a representative sample based on subject field, academic rank (lecturer, assistant professor, associate professor, professor), and institution type. Figure 1a-b summarizes the sample. The sampled transcripts were analyzed through a grounded approach to coding utilizing NVivo software. In some instances, key word searches were conducted across the entirety of the data set to probe more deeply on specific topics. This study does not purport to be statistically representative, rather, we hope the findings and recommendations of this report will provide a basis for future research and investigation. The interviewees remain unidentified in this report to protect their anonymity, but we thank the interviewees for their participation. Elizabeth Yakel and Roger Schonfeld gave feedback on a draft of this report and we thank them for their comments and insight. We also thank the 26 institutions that took part in the research as well as ProQuest for their support of and participation in this project.

\section{Defining Teaching with Primary Sources}

A project framed around the concept of "primary sources" must necessarily wrestle with defining what is meant by the term. This is no easy task. What makes a source "primary" is more a function of the question being asked of the object than some inherent quality of "primaryness" in the object itself. While certain classes of materials, e.g. letters, journals, and manuscripts, lend themselves more explicitly to the category of "primary source," other classes of materials can occupy a grey area between primary and secondary depending on perspective and research question, newspapers being a classic example. The issue is further complicated by the fact that different disciplines may define the term in different ways, and may consider the same object primary or secondary based on their research agendas. An emerging question is the status of datasets as primary sources, a clear indication of the expansiveness of the term in the digital age. The fluidity and instability of the term presents challenges to designing effective supports and services for the general academic community. However, this fluidity also makes primary sources a vibrant locus for collaboration and cross-pollination.

To make this project manageable, it was necessary to provide some constraints on what constituted "teaching with primary sources." For the purposes of this project, we defined primary sources as, "historical or contemporary human artefacts which are direct witnesses to a period, event, person/group, or phenomenon, and which are typically used as evidence in humanities and humanistic social science research." Datasets were not included as part of this definition to focus the research on the pedagogies of teaching with archival, special collections, and museum materials (and their digital counterparts). ${ }^{8}$ The working definition was used to identify instructors whose teaching could be considered in scope for the project and therefore an appropriate candidate for an interview. It is, however, important to note that while this definition was used to select interviewees, the interviewees did not necessarily need to share the same definition of primary sources, nor did they need to adopt that definition when discussing their teaching. Indeed, instructors held a wide range of views on what constituted a primary

\footnotetext{
${ }^{8}$ Ithaka S+R is currently fielding a project on teaching with data in the social sciences: Danielle Cooper and Rebecca Springer, "Launching Two Projects on Supporting Data Work," May 14, 2020, https://sr.ithaka.org/blog/launching-two-projects-on-supportingdata-workl.
} 
source, and while we were especially interested in the use of archival and special collections materials, it was important to capture the full range of resources instructors considered to be essential for their teaching.

Instructors likewise described a wide range of primary source pedagogies. Some described assigning their students primary sources through a reader (either a published sourcebook, or collection assembled by the instructor themself) while others designed their entire course around a specific archival collection at their institution. Instructors used original manuscripts in parallel with edited volumes to point out the critical differences, and others described trying to replace their course textbooks with primary source collections to save students money. Most relied on physical primary sources to drive student engagement and spark awe, while also noting the importance of moving beyond these initial reactions to analyze physical qualities, such as scale and production quality. Many described incorporating "show and tell" sessions in their courses, though occasionally questioning their value to the overall course. A few instructors saw such sessions as springboards that allowed them to better teach with digital sources in subsequent class sessions. Capturing this broad range of teaching practices, and the varying levels of engagement with primary sources they entail, was an important component of the project. The different challenges these widely different engagements pose for instructors will be discussed more fully below.

As this project focused on a kind of teaching rather than a subject area, the academic fields represented in the interview sample were quite broad, though with concentrations in certain disciplines (See Figure 1). Of the roughly 300 interviews, nearly a third came from instructors in history departments, where primary sources and archival materials are considered foundational objects of inquiry. English and art/architecture/art history departments were the next most represented fields in the sample. Beyond these concentrations, the interviews varied considerably across the humanities and humanistic social sciences, including instructors in journalism, anthropology, and earth and environmental studies. Though this project did not include STEM fields, engagement and collaboration with STEM disciplines is an important and growing trend for special collections, archives, and museums, and deserves further study to understand how their use of these collections could be better supported. 9

\section{How Instructors Discover Primary Sources}

Finding the right primary source materials for their courses is a significant challenge for instructors. Indeed, as the amount of available materials continues to grow through digitization efforts, vendor offerings, and the explosion of born digital content, instructors are increasingly met with a bewildering array of resources to choose from and sift through. The challenges they face and the strategies they adopt to overcome them are discussed herein.

\footnotetext{
${ }^{9}$ L. Anderberg, "STEM Undergraduates and Archival Instruction: A Case Study at NYU Polytechnic School of Engineering," The American Archivist 78.2 (2015): 548-566; Amanda H. Brown, Barbara Losoff, and Deborah R. Hollis, "Science Instruction Through the Visual Arts in Special Collections," portal: Libraries and the Academy 14.2 (2014): 197-216.
} 


\section{Teaching to Your Strengths: The Role of Research in Discovery}

A key source of dynamism (and tension) in higher education instruction is the fact that instructors are usually also researchers. Because of this, students, at least in theory, benefit by learning about the most current thinking on a given subject, as one instructor explained, "teaching should also reflect changes in scholarship, right?" Instructors also benefit from overlap between their research and teaching, and many interviewees noted that they used their classes to explore new topics, test their ideas, and develop new questions. The role of primary sources in facilitating this exchange, however, is not always straightforward.

When instructors teach in their subject area, their own research processes can be quite effective in identifying appropriate materials for their teaching..$^{10}$ Beyond specific research techniques, instructors can further rely on a wealth of knowledge and tacit expertise that researchers build over the course of a career navigating archives and special collections. Thus, because primary sources form the foundation of many fields of research, instructors can identify new sources simply by staying current in their field. Indeed, for many instructors this may be a more effective and efficient discovery method than relying on publishers or vendors alone, as one instructor explained, "it's not that a lot of new source books are being published, but there are works coming out. You know, scholarly works that have primary text in them.” New scholarly treatments of primary source materials such as manuscripts or works of art, or even new discoveries entirely, can also aid instructors in finding sources with which to teach. It is also important to note that scholars' and students' interests can converge, and as both the academy and students have become increasingly focused on recovering the voices of marginalized populations and other underrepresented groups, new scholarship can bring to light new materials or new readings for instructors and students.

Instructors also rely on their professional networks to discover primary sources for their teaching, as one interviewee noted, "whenever I teach classes that are related closely to my research interest, I usually also have a sense of who else in the country is teaching on a similar topic.” Such sharing of information is almost always done informally, however, and typically relies on personal relationships or chance encounters at venues such as conferences. More formal or regularized sharing of information and resources may, however, happen at the departmental level or with peers within the institution. As one instructor said, "I've tended to be more reliant upon speaking with peers, looking at comparing to syllabi really with other professors who are teaching courses that are similar, and practically speaking this is much more important in terms of how I process what's a good idea, what's a new possible source to introduce."

\footnotetext{
${ }^{10}$ For more on scholars' research practices see Jennifer Rutner and Roger C. Schonfeld, "Supporting the Changing Research Practices of Historians," Ithaka S+R, December 10, 2012, https://doi.org/10.18665/sr.22532; Matthew P. Long and Roger Schonfeld, "Preparing for the Future of Research Services for Art History: Recommendations from the Ithaka S+R Report," Art Documentation 33 (Fall 2014): 192-205; Danielle Cooper and Katherine Daniel, "Supporting the Changing Research Practices of Asian Studies Scholars," Ithaka S+R, June 21, 2018, https://doi.org/10.18665/sr.307642; Danielle Cooper, Cate Mahoney, and Rebecca Springer, "Supporting Research in Languages and Literature," Ithaka S+R, September 9, 2020, https://doi.org/10.18665/sr.313810.
} 
Primary sources discovered in the course of research do not always lend themselves to use in undergraduate instruction, however. Many instructors do not necessarily teach in their research area, or teach mostly introductory courses whose scope is much broader than any academic specialty. Instructors are also concerned that their research area is so niche that it would not be of interest to their students, thus one instructor, "my teaching is connected to my research but I try to not tie them too closely together because I don't want students to get bored by the minutiae of whatever my research is." A much broader issue is that students, unlike their instructors, often do not have command of the languages a primary source may be written in, as one instructor explained, "there is not much connection between the research and the classes that I teach. I find it difficult to do it. Also, because I do rely a lot on primary sources, and most of the sources about Argentina are in Spanish.”

Wedding the two roles of instructor and researcher is thus not always seamless or mutually reinforcing, and instructors themselves hold different views on the extent to which it is appropriate or effective to tie the two together. Developing a sense of how and when to do so can take years of experience and trial and error. For this reason, instructors must rely on more than their own research practices to find suitable primary sources, and engagement with their own institutions' collections can be especially fruitful.

\section{Looking at Home: Discovery in Institutional Collections}

Special and archival collections play a critical role in primary source based pedagogy. This is especially true when a physical encounter with an object is critical to achieving learning objectives (the issues surrounding physical and digital materials are discussed in detail below).

Yet finding local resources that are suitable for in-class use is not always straightforward or easy, especially when considering the overlapping and sometimes conflicting domains of library databases, cataloging systems, siloed collections, and the institutional memory and personal knowledge held by collections staff. Knowing where to look or whom to ask on campus can in itself be a major hurdle to finding and using institutional collections.

Faculty deploy a variety of strategies to find primary sources at their institutions suitable for their teaching. Perhaps the most important strategy noted by instructors was cultivating relationships with archivists and special collections librarians, and suggests the emphasis given to relationship building in the profession has yielded productive results. ${ }^{11}$ Most instructors who taught with institutional resources spoke of the importance of staff knowledge of the collection for their ability to find materials, as one interviewee noted, "[The archivist] knows her materials so well that she could suggest to me some absolutely entirely unexpected primary sources that I would never have even known to look for." Workshops and other on-campus engagements can also be effective in highlighting available resources, as another instructor commented, "I didn't realize that it [the library] had holdings that I could use in my Renaissance and Medieval classes really until the workshop that you organized." Such outreach can be critical for early career

\footnotetext{
${ }^{11}$ See for example, Sammie L. Morris, Tamar Chute, and Ellen Swain, "Teaching with Archives: A Guide for Archivists, Librarians, and Educators," in Teaching with Primary Sources: Trends in Archives Practice. Chicago: Society of American Archivists, eds. Lisa Janicke Hinchliffe and Christopher J. Prom (Chicago: Society of American Archivists 2016).
} 
faculty, who lack the requisite institutional knowledge. As one interviewee noted, new faculty may have an especially difficult time if they are transitioning between different types of institutions, "Many of them will be coming, maybe, from research universities where they've had access to primary sources. So part of it is orientation for a new colleague to figure out what do we have, and... I don't even know how I figured that out." What is more, such early outreach can be critical to developing long-term relationships, and many instructors noted how their collaboration with archivists and librarians has grown and evolved over time.

Close collaboration between instructors and collections staff can be extremely fruitful, and more will be said about such collaborations in the classroom below. However, it is also important to account for a variety of instructor discovery styles, as well as the limitations of using archivists or librarians as principal discovery tools. Few archivists or special collections librarians would claim to have perfect knowledge of their collections' holdings, and so their ability to direct instructors to appropriate resources is constrained by their own knowledge, interest, and length of tenure. This is further complicated by the fact that, even when collections staff have good command of a topic or collection, they may not have a perfect understanding of instructors' learning objectives or all of the nuances instructors are hoping to draw out through engagement with a primary source. The importance of the catalog and finding aids cannot therefore be overlooked, as one instructor explained his workflow, "And for Special Collections, I just use the online catalog primarily, although I do email the different librarians there and ask them specific questions about the museum, do you have this or that?"

Archival, special collections, and museum catalogs can, however, present significant discovery challenges to instructors. Catalogs may be incomplete or their metadata lacking, and archives, special collections, museums, and library catalogs may be kept separate from each other. One instructor noted that institutions may prioritize cataloging certain kinds of objects over others, complicating discovery, "I'd say the biggest challenge has to do with cataloging of materials...Special Collections had done in the years previous a really wonderful job of cataloging their book collection but had not really done anything on non-book materials.”

Instructors may also desire to know specific information about cataloged items. For example, many instructors teaching in areas where the language of the primary source materials is not in English may desire to find objects that contain images that could allow students to still engage with the source through visual analysis. As one instructor explained, "I wish that there was a simple way to search for only books that have pictures, you know...instead I just laboriously went through every book that was listed as being published in what I call the "Italian Renaissance' and check to see if it had in the details, if it mentioned images." Several instructors noted, however, that, unless it was also for their research, they simply didn't have the capacity to dedicate so much time to searching for suitable materials in this way.

While the need for better and more complete cataloging is generally well known, it is also important to highlight that instructors approach discovery from widely different perspectives as well. Some approach the process of discovery in a more open-ended fashion, allowing their teaching and research plans to be guided by what they find in the archives, as one instructor shared, "I never find what I want. That's not how it works. I have no idea how this is all going to 
piece together." Other instructors approach discovery in a much more pointed way, "I tend to have quite a clear sense of what it is that I'm looking for when I'm trying to track down a source that's going to fit in a particular part of the lecture."

These different approaches to discovery necessitate very different kinds of support and present different opportunities for collaboration. Instructors with more open-ended discovery methods are likely to rely more heavily on library or archival personnel, and may present greater opportunity for archivists and librarians to move upstream in the course development process and help shape a course around their collections' strengths. On the other hand, instructors who have a clear sense of the materials they want, or who need primary sources to "slot in" to their course may rely more heavily on catalogs and their own personal knowledge of primary source materials. Furthermore, in this latter case, it may be more difficult to find archival and special collections materials that are perfect fits for the course topic, and so may require more imaginative uses of materials to achieve learning objectives.

While most instructors highly valued the institutional collections available to them, most noted some difficulties in discovering the right materials to use in their teaching. It is clear that instructors value the expertise of library and archival staff, but also require more effective search and discovery tools. Providing the right balance between staff expertise and independent discovery is critical, and that balance will depend on individual workstyles. In either case, lack of knowledge about institutional collections was recognized as a significant challenge by many instructors, as one summed up, "What is challenging is when you're working with the collection whose content you can't fully know." Perfect knowledge of a collection is, of course, likely not possible, and many instructors also noted the thrill of making new discoveries in archives and special collections. Nonetheless, there exists a clear need to more fully support different discovery practices and approaches, especially in the areas of cataloging and non-textual materials.

\section{Looking Beyond Institutional Collections}

Many instructors noted that institutional collections were critical resources, though more so for

their teaching than supporting their specific areas of research. However, even the most extensive archives and special collections cannot cover the full breadth of instructor teaching areas, and the tension between locally held collections and the global interests of instructors was a recurrent theme through many of the interviews. To find the primary sources they need, instructors look to a variety of institutions and vendors beyond their own campuses, and, while most expressed great optimism and enthusiasm around the ever-increasing availability of primary source materials, they also held growing concerns about their ability to sift through this expanding body of material and find high quality and appropriate primary sources.

Beyond their home institution's collections, instructors rely on other institutional collections that are either within visiting distance from their home campus or that have digitized significant portions of their collections. These institutions can include museums (ranging from major museums like the Metropolitan Museum of Art to local history museums), archives (again, ranging from national archives to local archives), and other college and university collections 
within and beyond the United States. When working with these collections, instructors did not typically note working with collections staff at these institutions (or at their home institutions), save for the cases where they were physically bringing their students to the collections. Instead, instructors rely on the digital resources these institutions make available. Here, instructors encounter many of the same difficulties in searching through these external institutional collections, and in many ways these issues can be compounded, as one instructor explained, "If you are looking for a particular text, but that text is in a couple dozen manuscripts, you don't want to search through 24 different library catalogs all over the world to see where there's a digitized copy. And so if there were a unified directory...to digitized manuscripts, that would be really helpful."

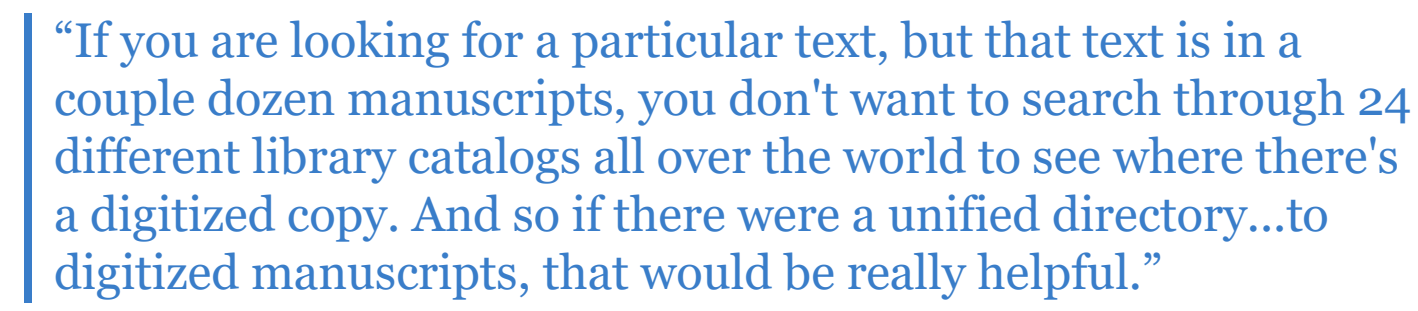

Discovering where sources exist and are accessible can be a research project in and of itself for instructors and, sometimes, their students. One instructor recounted, "One of the projects that we did was to go find where some of these collections exist and if we can't get access to it, and a lot of these are things that are in the National Archive in the United Kingdom, which is notoriously awful for digitizing and cataloging things." Many other instructors noted the time they had to devote to searching through various institutions' collections to find materials and that this made up a significant portion of the time it took to develop or plan their courses. While instructors relied on a variety of databases and search engines, Google was repeatedly cited as a critical discovery tool, and some instructors pressed further in explaining that Google was helpful not just in finding sources, but also in determining which source was most practicable to include in their class: "I think Googling comes in terms of looking up what is still in print, right, and sometimes that is a very tricky thing for older text. So, the Googling part is more for kind of practical aspects of finding out what text is actually doable."

A further complexity when working with such collections is the copyright status of their digitized materials. While not all instructors were equally attuned to the copyright issues surrounding primary sources, it was an especially important consideration for instructors who intended their students to use the materials to create a public output, like an exhibition or YouTube video. Digital collections were not the only area of concern regarding copyright however. Many instructors relied to varying degrees on sourcebooks, especially for large or introductory courses, as one instructor explained:

In my 202 class, where I was trying to find primary sources for periods that I am no expert in at all, I sometimes will just do searches on the catalog, like, you know, 19th century primary sources, something like this and I found a number of books that were compilations of primary sources. I quickly found that those have horrific copyright 
policies and that you can almost not make a PDF of hardly anything out of those things without having to pay a huge amount of money.

Some instructors even described working backwards from textbooks and sourcebooks, looking up the primary sources they cited and then searching through the library catalog and other collections to find those sources (or similar) with more usable terms. In the face of these challenges, many of the interviewees who raised the issue of copyright also noted relying on the expertise of librarians to help them work through the relevant copyright issues and find usable materials, making them valuable partners even when working beyond their institution's collections.

Beyond the digital collections held by other institutions, instructors also noted relying on vendor databases to find primary source materials. Reliance on curated databases was especially noted when instructors were teaching outside of their research areas, and so less familiar with the available materials. Many instructors found these resources especially important for enabling them to encourage their students to discover primary sources on their own as these databases provided more of a "sandbox" environment than the open web. Instructors also noted the importance of specific vendor collections, as one related, "I rely on JSTOR and [EBSCO's] America: History and Life a lot. And also all the ProQuest historical newspapers, especially the historical black newspapers, Chicago Defender, Amsterdam News, a lot of the other ones have been-Ethnic NewsWatch has been incredibly useful for me for the primary sources." 12 As this instructor makes clear, curated collections of sources are especially helpful for both instructor and student discovery, and many interviewees recalled the names of the collections they used frequently, with various historical newspaper collections being far and away the most cited.

Non-tenured or contingent instructors may hold slightly different views about vendor resources, however. Because such faculty may move between institutions with some frequency, or in the case of adjuncts, teach at multiple institutions simultaneously, they can not necessarily rely on every institution subscribing to the same resources. To avoid having to completely redesign a course for every institution, such instructors may instead prefer to incorporate open access resources. As one instructor explained of their choice of sources, "it's something that might change down the line, mostly because I knew I've been moving around a lot, the past couple years I've tried to stick with more open-source collections.” As higher education has come to rely more and more on such contingent faculty, understanding how best to support them and their specific needs deserves further consideration.

Finally, it is also important to reiterate the connection between vendor databases and instructor discovery through their scholarly research, "those typically are secondary sources, but sometimes you can find, you know, articles that incorporate primary sources like one that I'm sharing, which is a translation with an accompanying essay of a document that was produced in the 19th Century that, you know, I get that from JSTOR and the students get it from there when they use it in the class." Thus, while specific vendor created collections of primary source

\footnotetext{
12 Note that JSTOR and Ithaka S+R are both services of ITHAKA.
} 
materials are much valued by instructors, their holdings of secondary scholarly literature is also quite important, though perhaps more difficult to sift through for non-specialists.

\section{Discovering Primary Sources: Present and Future}

Instructors deploy numerous strategies to locate primary sources that are suitable for their teaching and rely on a host of library, archival, and vendor resources. Considering all of these resources together, instructors expressed a mix of excitement and concern about their ability to discover the right primary sources for their classes now and in the future.

Discussed with equal parts excitement and trepidation was the growing availability of primary sources, through research, collection digitization efforts, and vendor databases. Instructors were concerned that as more and more became available, it would become more and more difficult for them to separate the signal from the noise. There is also concern that digitization initiatives will, for any variety of reasons, fail to completely digitize all of a collection and so give a false impression as to what in reality exists. Likewise, the atomized or uncoordinated nature of many of these initiatives means potentially more work for instructors as they have to become familiar with a growing number of collections and their associated database interfaces and architectures. Indeed, instructors already describe utilizing a large number of online discovery platforms beyond their library's catalog, including, the Library of Congress, ProQuest, EBSCO, Hathi Trust, JSTOR, Artstor, the Metropolitan Museum of Art, EEBO, Kanopy, Instagram, NYPL Digital Collections, State Archives Digital Collections (Illinois \& Texas), Readex, HistoryMakers Digital Archive, and any number of specialized databases, in addition to Google, Twitter, and YouTube. The proliferation of resources can thus pose a challenge to instructors, as one related, "Well, I'm hoping there will be more and more available primary sources that I won't have to go to 10 or 15 or 20 different sites to find individual bits and pieces."

These "bits and pieces" raise another important consideration for what kinds of primary sources instructors seek out for their teaching. Many instructors noted that length was a key issue in the case where they were looking for material to give their students. While instructors may consider an entire diary or manuscript for their research, most felt they could not expect their students to process such a large amount of information and typically looked for sections or even pages that were more appropriate for their students. It is also likely that this concern is why instructors spoke so frequently about using historical newspapers in their teaching, as news articles are, almost by definition, meant to be easily digestible. To support instructor teaching and student engagement, it is not enough to simply digitize more, but also consider how such resources will fit into a syllabus.

Considering end use and acting accordingly implies some form of curation, and instructors were also concerned about who got to make decisions about what was available and how to ensure what was made available was of quality. As one instructor explained, "I think the way it becomes really challenging, I can imagine this, it always happens, if more and more is there, then how is this curated? Who gets to say something about this and how to actually evaluate what is authoritative, what is usable academically, what may not be usable?" As evidenced by the many instructors who framed at least some of their lessons in archives and special collections around 
collection history and those left out of the archival record, curation is both an essential aid to discovery as well as an issue of growing concern. As instructors and students are not typically specialists in how collections are built, cataloged, and indexed, collections staff have an integral role to play in explaining how these issues impact representation in collections. Furthermore, as institutions and vendors continue to grow and refine their collections, collections staff will need to empower their various constituencies in this way so that they are able to ask the right questions and demand greater transparency and accountability.

When considering teaching with primary sources, how instructors find materials is only part of the equation. Equally important is how students are enabled to discover primary sources for their coursework and general interests. When turning to the issue of student discovery, we find many different challenges, and so it is to students that we now turn.

\section{Student Discovery}

While most instructors have well-developed research skills to aid them in the discovery process, the same is generally not true for their students. Though teaching such research skills may be one of the principal goals of higher education, and instructors themselves note the importance of teaching these skills, they nonetheless struggle with how best to go about it. Instructors are concerned about the time it takes to find appropriate sources and worry their students will be discouraged or gravitate toward low quality sources. As a result, it is much more common for instructors to provide primary sources to their students directly, rather than allowing them to discover sources on their own. Facilitating better discovery, for both instructors and students, is thus a critical issue for primary source based pedagogy and requires close collaboration between instructors, librarians and archivists, and vendors.

\section{Digital Resources and Databases}

Instructors generally took a dim view of their students' ability to find primary sources on their own, and consequently, generally only required their students to do so in upper level courses and small seminars where they could devote sufficient time to guiding them through the process. ${ }^{13}$ Instructors' principal concerns typically fell into one of the following categories: concern over the quality and relevance of the sources they would find, concern that students did not have the subject expertise to find appropriate materials, concern that challenges in the discovery process would discourage them from further engagement, and, related, that students did not have, or would not devote, the time necessary to find appropriate primary sources. Most of these concerns can be understood as different aspects of the broader issue of information literacy, especially the areas of source criticism and efficient discovery. Though instructors did not, generally, discuss the concept of "information literacy" per se, instead using terms like media literacy, critical thinking, and the like, it is nonetheless clear that primary sources are a class of materials where information literacy issues are especially top of mind, and therefore, an

\footnotetext{
${ }^{13}$ For a comparison of search strategies and efficiency between undergraduates and other academics, see Morgan G. Daniels and Elizabeth Yakel, "Seek and You May Find: Successful Search in Online Finding Aid Systems," The American Archivist 73, no. 2 (2010): 535-68, http://www.jstor.org/stable/23290758.
} 
ideal opportunity for fruitful engagement and collaboration. Indeed, while instructors did not dwell long on the issues of "fake news," misinformation and disinformation, and the existence (or nonexistence) of objective truth, ${ }^{14}$ it seems likely that instructors will increasingly try to address these topics through primary sources in the future, as one instructor said, "I tend to gravitate towards it [teaching with primary sources] because I like to be a soap box for there was fake news in the 17th century, too."

Google, unsurprisingly, loomed large in instructors' discussions of how their students find information, and many instructors devoted at least some class time to addressing searching on Google: "Our students Google, that's just what they do. So, I will go through with them in class. How to do a simple Google search, but not just a Google [search] where like the first three things you get are what you're going to get." Getting students to look beyond the first few hits in a Google search was a recurrent hurdle many instructors noted, as well as getting students to evaluate the quality of the sources. As one instructor explained, "we talk about scholarly sources and digital databases versus, you know, Kate somebody's website, blogspot.com."

Beyond these specific Google search challenges, it is clear that Google has effected a much more profound shift in student information habits. The ubiquity of Google in students' daily lives has encouraged the perception that its search engine will provide access to exhaustive and complete information, when of course, there is a great deal that Google does not or cannot capture, especially in the realm of primary source materials. Fighting this perception is critical, as one instructor noted, "The largest challenge is they expect everything to be online," while another summed up the problem even more pithily, "If they can't find it online, it doesn't exist."

It is perhaps ironic (or perverse, depending on your point of view) that online resources might seem more real for students than a library's physical collections, but recognizing this tension is critical for facilitating better student engagement and discovery. Vendor databases may provide a helpful bridge, as one instructor remarked, "Students have become so-it's so easy for them to Google, so things like ProQuest makes that easier for them." Vendor databases are not, of course, the same as Google, and while these resources can expand access to primary sources in students' preferred medium, instructors noted several challenges their students face. One instructor explained the importance of ease of access, "I'd like to assign publicly available ones as opposed to [commercial database] just because, the things behind paywalls, even though I know students theoretically have access to them, I found that they are much more likely to readily engage with and explore collections that are just a click away." Many instructors echoed this experience, relating that even if they tell their students to use specific databases, students will frequently just use Google to find the database, often hitting a paywall.

In several cases, instructors cited the library's own catalog as a major impediment to students' gaining access to databases and institutional collections, as one instructor related, "[The library catalog] is a nightmare and, in many ways, sets back teaching students how to do research. And,

\footnotetext{
${ }^{14}$ For a recent reflection on these issues, specifically on how they intersect with information literacy, see Roger Schonfeld and Lisa Hinchliffe, "Truth and Lies," The Scholarly Kitchen, January 1, 2021mhttps://scholarlykitchen.sspnet.org/2021/01/19/truth-lies/, as well as the lively response in the comments.
} 
you know, I don't know anyone in history who isn't frustrated with it. And because it sort of steps-it stands in the way of students figuring out that databases cover certain kinds of material." Instructors also explained that their own frustrations with their library's catalog also impacted students, and that even the most helpful and knowledgeable staff cannot entirely compensate for deficiencies in the catalog, "Even with the intense one on one contact that I had with all of the fabulous staff here, it still is kind of hard to navigate the online catalog and even to get a really sense of the value of what these resources are. And so it's hard to bring students in when you yourself don't even know what's there."

Instructors further noted that students may have trouble navigating within and between the catalog and vendor platforms and struggle to make sense of varying interfaces and database architectures (issues with which instructors themselves may struggle), as one explained, "Often students would come back talking about 'I didn't like that interface,' or 'I would have much rather just Googled it, it would have been easier." In addition to student discomfort with database interfaces, instructors also note a deeper issue in that students often do not recognize why they should bother searching these databases to begin with, as one instructor observed, "For them it's not really clear why would a search of an EBSCO journal article database produce things that a Google search, or if they're a little bit more sophisticated, a Google Scholar [search, wouldn't]...they don't understand why it's necessary, why they would get things that they couldn't otherwise get." While this instructor referred to secondary sources, it seems likely that the same could be said of students as they try to find primary sources as well.

Some instructors may try to correct this perception through their own pedagogy, as one instructor explained, "We go to different libraries and we use different search engines and, you know, we get different results, even though they might have similar books and collections, and so [we] get the students to think about, like, every place has different search algorithms and those produce different results." Several instructors noted giving similar assignments to their students, but, in general, they were not sanguine about their students' ability to appreciate the difference, as one instructor noted, "Occasionally there will be a realization 'oh this is actually quite good and this is different from the stuff I found on Google.' But that's exceptional. Most people just view it as kind of a tedious burden to finish an assignment that's worth 10 percent of their grade."

Beyond these technical challenges, instructors also noted that students typically do not have the requisite domain knowledge to find appropriate sources. Many instructors noted that primary sources required greater knowledge, experience, and skill to find, in comparison to secondary literature, "I usually like to give them the primary sources because those are typically the harder things to find and I think those are the things that require more subject matter expertise, right?" Instructors may find this problem especially acute when teaching large classes with students from different majors and grades. However, it is important to note that, in some cases, instructors encouraged students to use secondary literature to find primary sources, in a manner similar to their own discovery practices, as one instructor reflected, "I find actually, the students that find ones on their own are almost always... really motivated students that have just delved already into the research of secondary sources and that, as I often advise them to do, the whole 
class look[s] in the footnotes of the secondary sources and see what the people are citing and then go to that."

In larger or more mixed classes, instructors may think it unnecessary or overkill to require students from outside the humanities to learn to use specific databases. As one instructor noted, "There's lots of students who are not history majors, and I think it could become very frustrating, and I don't see the point for an engineering major to, you know, learn how to use HAPI [the Hispanic American Periodicals Index]." Student frustration was a common concern among instructors regardless of major or grade, however, and instructors were especially concerned that frustration during the discovery process would lead discouragement and disengagement, as one instructor related, "I find a lot of younger people- they just get discouraged. They put in, you know, the name of what they're looking for and they don't get what they want, then they just say, 'Well, I can't find anything.' I think that's the challenge."



A related concern was the amount of time it takes to search and find primary sources. As already noted, instructors see that their students expect the kinds of immediate results and access provided by Google, and the increased time it can take to sift through different library or thirdparty databases can add to their students' frustration. It is also important to note that instructors do not see this solely as an issue of student impatience or laziness. Many instructors understood that their students had many competing responsibilities and interests and so chose not to focus on source discovery, instead prioritizing other learning goals such as source criticism or visual analysis.

\section{Physical Collections}

The preceding discussion of students' ability to find primary sources independently has mostly focused on digital resources and online database platforms. It is of course also important to consider how instructors view their students' ability to find and work with the physical collections held by their institution, whether in the library, archive, special collections, or museum. Instructors tended to be even more skeptical of their students' ability to find and access physical resources located on campus. Notably, though instructors overwhelmingly believed in the value and importance of institutional collections, they rarely required or expected their students to make use of these resources independently. That is, most instructors expected their students to utilize their campus' physical resources only through specific class sessions devoted to such material and framed around primary sources selected in advance.

Instructors tended to ascribe their students' reticence to use physical resources to similar issues mentioned in the previous section. For example, some instructors noted that the immediate results and access they experience through Google affects not only their willingness to use other 
databases, but also their willingness to go to the library to engage with a physical source. Others saw a distinct lack of knowledge in how to approach library materials to begin with, "They have no intimidation about just doing online research and going into the Met's giant website with all of the different sections and that's normal for them...on the other hand, they are very-they're less confident about leaving that kind of data source and going to the stacks in the library, or going to a facility and seeing materials."

Students' lack of comfort or confidence in working with physical resources and browsing stacks was stressed by multiple times, and often contrasted to students' preference for online options:

From the experience of bringing students to the archive or the [special collections] room, [there is] a kind of fear of just poking around. I mean, I think when they're online poking around, there is a lot of clicking and clacking and no one's watching...I think [there is a] fear of not knowing what they're doing standing in front of those books and how to approach it.

Instructors similarly noted that their students were increasingly unaccustomed or reluctant to ask for help from staff: “They're more self-serve. That's their-that seems to be their first instinct." Such a preference poses obvious challenges to accessing archives and special collections where self-service is rarely an option. Despite, or perhaps because of this notable reluctance to ask for help combined with an uncertainty or discomfort over how to approach physical collections, instructors often noted they regularly encouraged their students to consult library staff, though they were either uncertain or pessimistic about how many students actually did so.

\section{Balancing Curation and Open Discovery}

Instructors perceive a wide range of issues and challenges in their students' ability to discover primary sources independently. This study focused on instructor practices and views, and a natural next step would be to study student practices to better understand the extent to which instructors' perceptions accurately capture their students' actual practices. However, regardless of how accurate instructors' perceptions may be, these perceptions are what ultimately guide their pedagogy, and so it is important to examine how these perceptions shape their teaching and course design.

Even though instructors almost universally upheld the outstanding value and impact of teaching with primary sources and its centrality to their teaching (as one instructor said, "I can't think of not teaching with primary sources ever...it's so much part of everything that I do"), their lack of confidence in their students' ability to discover them on their own typically means that they provide students with primary sources directly. When asked how their students typically found primary sources, instructors frequently gave answers like, "I provide everything for them"; "When I ask the students to do research using a primary source, I provide it"; or similar. Some instructors noted that they have tried to have their students discover primary sources on their own, but met with little success One recalled, "I would love them to locate the material themselves. I have tried that and it has failed miserably.” In cases when instructors expected 
their students to find primary sources beyond what they provided for them, they noted having to heavily direct the process, "I direct them to the museum. I direct them to the museum's online collection. I direct them to Special Collection's online catalog, and I direct them to the galleries that Special Collections have."

As one might expect, the level of the course impacted the extent to which students were expected to find primary sources on their own. However, even though instructors noted that in their upper division courses they more frequently required students to find primary sources independently, it was still quite common for them to provide the sources directly or heavily direct the process. Comparatively few instructors explained how they expected their students to gain the necessary skills to be able to find primary sources independently. This would seem to mirror the teaching of research skills generally, in that instructors feel it is too advanced for lower division courses, but expect students to already have these skills by the time they enroll in upper division courses. The fact that many instructors think finding primary sources is more challenging than secondary ones only compounds the problem.

Though instructors most commonly reported giving their students primary sources directly, some did relate how they tried to build up student skills, and confidence, over the course of their class, "I haven't always given [primary sources] directly to them and said, you know, 'Go find one of these or two of these books or articles or whatever and do it,' but I am hoping to, you know, get them to build up their confidence and sort of moving out with the next paper and then maybe the third paper because there's three papers in this class." Using multiple assignments that gradually build skills, as in this example, was a common strategy related by instructors. Building on this, instructors also noted pointing their students to finding aids to get them started in a particular direction, but also that not all of the areas where they teach have these resources.

Perhaps most significantly, instructors were frustrated in finding the appropriate balance between curation and direction on the one hand and allowing open discovery and the "eureka moment" on the other. One instructor summed up the various issues involved and is worth quoting it at length:

There's certainly an awful lot of people out there who are trying to figure out ways to monetize that. Right? And trying to figure out, 'Here's this collection we can publish for you. And here's this collection, we can edit this and make it a package that you can work with.' I mean, for me, one of the pleasures of working with primary sources, and those kinds of packagings...is I want to find a balance between-I try to find a balance between making it easy for the students but also giving them something still with a sense of discovery if they're working on their own projects...there's a difference between, 'Here we are working on class, I'm handing out a document for us all to read together.' And, 'Here's a way to get into a collection of documents. What do you find in there that you can do something with?'

This same instructor offered an important further insight: "I wish there were two or three or four caches of primary source material collections that I could point them towards that I had 
more of a sense of what was in there and that they would be-that I knew that they could find more stuff to work with." As this instructor demonstrates, instructors' own ability to discover and know the contents of collections directly impact their ability and willingness to facilitate student discovery. It is also clear that instructors see such sandboxed collections as a way to teach students discovery skills while not having to worry about issues of relevance and quality or, indeed, students' time, frustration, and discouragement.

Both instructor and student discovery practices and perceptions are critical aspects of course design and pedagogy. Identifying primary sources is, of course, only half the battle, and to better facilitate discovery, it is also important to understand how the material will be used in instruction. In the next sections therefore, we will look at how instructors plan their courses and how they actually go about teaching with primary sources. As we will see, instructors adopt a variety of pedagogies when teaching with primary sources in order to achieve their learning goals.

\section{Pedagogy and Course Design}

While discovery is a critical issue in primary source pedagogy, it is of course, only half the battle. Once appropriate sources are found, instructors must decide how to teach with them and how they want their students to engage with the sources. Though recognizing the recursive relationship between discovery and teaching, we focus on teaching separately for the sake of clarity and to highlight the specific needs of instructors when teaching with this kind of material. This is especially important in the case of teaching as, while instructors can rely on the research skills they honed in graduate school to aid them in primary source discovery, they often feel much less prepared for the work they do in the classroom. As a result, instructors' teaching practices are often developed through years of trial and error, frequently informed by ad hoc collaborations, chance discoveries, and random opportunities. There exists, therefore, significant opportunity to better support instructors in this area, and ample room for collaboration.

\section{"You Should Just Know": Learning to Teach with Primary Sources}

Despite instructors' great enthusiasm for teaching with primary sources, and primary sources' centrality in many humanistic disciplines, virtually every instructor interviewed noted that they received very little formal pedagogical training in how to effectively teach with them. This, of course, is part of a much wider trend in graduate education, which overwhelmingly focuses on research rather than teaching. While greater preparation for teaching generally is needed in graduate education, the complexities of teaching with primary sources are sufficient to warrant special focus.

"I got here and honestly was like a deer in headlights, had no idea what I was doing, so I had to figure it out," so one instructor described their introduction to teaching with primary sources. This baptism by fire experience was similarly expressed by most of the interviewees in one way or another, and a great many described their experience in learning to teach effectively as one of 
trial and error. In many cases, instructors noted it took several years for them to work out how to teach with primary sources comfortably and effectively, as one instructor recalled, "I learned to do that over many years, and I think maybe after five or six years of doing this, I felt reasonably comfortable that I was being effective." Of course, this trial and error way of learning potentially leads to several years of students being underserved.

Many instructors noted the importance of their own experiences in undergraduate and graduate school, noting that they based much of their teaching on that of their mentors and graduate advisors. However, in no instance did interviewees describe this modeling as an intentional or explicit part of their pedagogical training in graduate school, but rather something they were supposed to implicitly absorb. One instructor explained that when it came to learning how to teach with primary sources, the prevailing attitude seemed to be, "oh, you'll figure it out, you should just know." This sense that "you should just know" is a direct consequence of the implicit and informal nature of much of the professional training that occurs in graduate education, but often results in a sense that if one does not "just know" then it is a failing of the individual and not the structure of the program. Perhaps this helps to explain why a greater emphasis on pedagogical training has been so hard to effect, despite growing calls for it. ${ }^{15}$

It is also noteworthy that several senior instructors noted that they offer much more comprehensive pedagogical training to their own graduate students, as one explained, "I didn't have any pedagogy training really whatsoever...there was one pitiful little token pedagogy workshop thing I had to go to before I taught that one section in 101 as a graduate student, but compared to the teacher training we offered our graduate students, worlds apart." While it may be the case that these specific departments are offering more professional training to their students, it was still notable that most junior instructors related more or less the exact same lack of pedagogical training as their more senior colleagues.

Given the lack of preparation in graduate school, most instructors noted the importance of learning on the job, and the role that their colleagues play in the development of their pedagogy. Many instructors noted sharing syllabi and other resources and that such sharing is especially important for new instructors or those teaching new courses: "I've sent syllabi for all kinds of courses. Obviously, within the [institution] community, within my department, but also to people who are starting out trying to teach new courses." In addition to sharing syllabi, many instructors noted that conversations with their departmental colleagues and observations of one another's teaching were likewise critical: "I've tended to be more reliant upon speaking with peers, looking at comparing to syllabi...practically speaking[that] is, you know, much more

\footnotetext{
${ }^{15}$ Major professional associations in the humanities have called for doctoral programs to increase the amount of pedagogical preparation they offer to graduate students. Jim Grossman, "To Be a Historian Is to Be a Teacher," Perspectives on History (November 2015), https://www.historians.org/publications-and-directories/perspectives-on-history/november-2015/to-be-a-historianis-to-be-a-teacher; "Report of the MLA Task Force on Doctoral Study in Modern Language and Literature," Modern Language Association, May 2014, https://www.mla.org/content/download/25437/1164354/taskforcedocstudy2014.pdf. See also Leonard Cassuto and Robert Weisbuch, The New PhD: How to Build a Better Graduate Education (Johns Hopkins University Press, 2021), and Katina Rogers, Putting the Humanities PhD to Work: Thriving in and Beyond the Classroom (Duke University Press, 2020).
} 
important in terms of how I process, you know, what's a good idea, what's a new possible source to introduce."

In the domain of teaching with primary sources specifically, some instructors noted the importance of learning from their colleagues in archives and special collections, "Frankly, I defer a lot to archivists who've done classroom work a lot before because I've learned a lot from watching them teach how to work with primary sources." 16 Though not every instructor noted learning from archivists and librarians, most interviewees noted including them in some capacity in their courses (e.g. a one shot session in the archives), and, given the major role of learning by example in their graduate training, it seems likely that such experiences also shape their teaching practices, even if this not always made explicit or formally recognized.

Despite, or perhaps because of, the dominance of this informal or implicit model of pedagogical training, several instructors expressed interest in and the need for more focused training. In the realm of primary sources, one instructor summed up the particular challenge neatly: "I'm still learning how to approach [teaching with primary sources], because different sources, I think, require different approaches. It requires a different approach to a digital primary source than a written one. Something in translation, I feel like you have to sort of deal with in a different way than something that's in the original language." As databases, platforms, and tools multiply the number of available sources and the ways of engaging with them, more explicit training will likely become increasingly necessary, though this will likely require a broader, concomitant shift in culture away from the implicit "you should just know" paradigm. Nonetheless, interviewees did express interest in such training and resources, as one instructor opined, "I would like to read something on how do you teach with primary sources. I think that would be interesting, because it's, again, it's not just the material but it's the pedagogy."

Given this expressed interest, it is also worth noting that clear communication, i.e. specifically tailoring communication and outreach to different constituencies, is important. One instructor described their reaction to a campus initiative on training faculty to teach with primary sources in the following way, "It was an invitation that was greeted with a certain amount of bemusement on my part, because primary sources are the building block of history courses, and so I was bemused to see the claim of authority from outside of myself...But I was also kind of staggered to realize in the call that I didn't particularly make use of repositories on campus." Understanding how instructors might respond to such offers of support and tailoring the message to meet instructor's own perceptions of their knowledge and skill, will be critical.

\section{Course Design: Teaching with Primary Sources in Large Classes}

While more and better pedagogical training is both desired and needed, instructors nonetheless design successful courses in which primary sources play an important role. However, the way in which instructors teach with primary sources, how they are built into their syllabi, and how

\footnotetext{
${ }^{16} \mathrm{~A}$ recent survey found that librarians and archivists, like their colleagues in other disciplines, receive little formal training as teachers and are expected to learn how to teach with primary sources through trial and error. Lindsay Anderberg, et. al., "Teaching the Teacher: Primary Source Instruction in American and Canadian Archives Graduate Programs," The American Archivist 81:1 (Spring/Summer 2018): 188-215.
} 
students are expected to engage with them is heavily influenced by the size of the class. To highlight the specific challenges of designing engagements with primary sources in both large and small classes, instructors' practices will be discussed separately, starting with large classes.

In larger classes, instructors' learning objectives with primary sources tended to focus on sparking interest and engagement with the course subject matter, as one instructor put it, "just something you want the students to experience or try that, you know, they haven't tried before." Other objectives focused on getting students to understand, if not yet put into practice, the ways in which the historical record, or scholarly argument generally, is constructed. Indeed, whether for a large introductory class or a small upper division seminar, instructors noted that primary sources were a critical resource for achieving their overarching goals, which often centered on different elements of critical thinking, as one instructor surmised, "I think it's really teaching students key historical skills to be able to assess evidence and develop arguments based on competing evidence. I mean those are central to history but they're also central to life I would argue."

As primary sources are seen as an important way to pique student engagement, instructors place great value on the "encounter" with a primary source. As one explained, "There's a kind of primal dimension to encountering an object that cannot always be put into a neat intellectual package and engaging in the encounter of the primary source can release things inside of you that you didn't know were there and that I think is exactly what we want students to do." As shall be discussed in the following section, the logistics for facilitating this kind of encounter in libraries and archives can be complex even for very small groups, and so it is not surprising that instructors struggled with how to facilitate equivalent experiences for larger classes. Though some instructors believed such engagements may be overkill for a large introductory course, many instructors noted the importance of primary sources in driving student engagement and interest in their discipline. One instructor recalled, "They have a romanticized idea of 'it's cool' to look at old stuff. I find that that's a very good thing to leverage and let them get from the cool to the sophistication of this." Designing engaging encounters with primary sources for large introductory courses, therefore, may be an important way to increase student interest.

The pedagogical value of teaching with primary sources has been explored above, and furthermore, working with primary sources gives students a more accurate understanding of the actual practice of many academic disciplines. One instructor reflected on their own experience as an undergraduate, noting the difference between their expectation of what history was and its actual practice as a discipline: "strangely, thinking back on it, as an undergraduate I was frequently frustrated by being given primary sources instead of a history book where people would tell me what the story really was." There is, therefore, much to be gained by developing engagements with primary sources in large introductory courses and not restricting them to smaller upper level courses, and has the potential to better meet instructor's stated learning objectives.

The logistical challenges herein are, however, well known, especially when trying to incorporate local collections like archives, special collections, and museums. The first and most obvious challenge is class size and space. Most spaces dedicated to teaching with collections cannot 
accommodate large class sizes, and, even if they could, having a hundred or more students huddle around a manuscript is a far cry from the intimate, immediate, hands on experience instructors and students find so valuable. It should be again noted that the research for this project was done prior to the pandemic, and it will be interesting to see if attitudes on this point have shifted, or, given instructors increased familiarity with remote engagements, if they have explored new ways to incorporate primary sources into their larger classes.

In person, instructors described several ways in which they tried to facilitate larger classes. In some cases, instructors may try to break up their class into smaller groups, or, in the cases where TA led discussion sections exist, use these sections to stagger time in archives, museums, and special collections. However, breaking up classes in this way has the effect of transmuting the problem from one of space into one of time, as this requires more time of instructors, TAs, and archivists, special collections librarians, and museum staff. Concern about overburdening these latter was mentioned several times in interviews. For example, one instructor noted that they preselected sources (rather than letting students discover sources on their own) to save the library staff's time, "If getting them to physically handle a 19th-century document...requires me to preselect the documents, I think that is a good idea, honestly. It just guarantees success, and it saves a lot of wear and tear on library staff."

Instructors' concern over staff capacity is an important issue to surface. While libraries, archives, and museums keep careful track of the use of their spaces and resources, they cannot measure the usage lost due to instructors' perceptions of staff capacity, whether those perceptions be accurate or not. Given the increased labor required for larger classes, clarity between instructors, staff, and the administration is especially important if concerns over staff capacity is not to stand in the way of developing more effective engagements with primary source collections.

Owing to these complexities and concerns, most instructors described only very limited (if any) engagements with physical primary sources in their large, introductory classes. Indeed, the definition of "primary source" tended to be most expansive when discussing such classes. Instructors tended to focus on "primary sources" as given in textbooks and readers, or displayable in a PowerPoint slide, and so of a different kind than the physical or digitized artifacts held in specialized collections. Instructors still found such primary sources to be critical and the real core of the class, and so rely heavily on such collections assembled by publishers. As one instructor explained, "In the gen ed courses...I'd have the same goals, to teach students to understand the ideas about religion and then to investigate specific examples...But I have to do more of the work ahead of time and rely more on printed collections for the gen ed classes, yeah."

Some instructors described the ways in which they tried to replicate the kinds of engagements with primary sources typical in smaller classes in their larger surveys. One instructor, for example, described how they tried to do this with through group work: "I still assign primary sources to that end, we talked about primary sources in lecture class, we had dedicated time to-even in a close to 200-person class, it didn't always work, but I committed to it, to breaking into small groups and talking about it." Another described how his mentor structured her course 
assignments around engagement with one primary source over the course of the semester, though noting that this was unusual:

She was deeply committed to making the big assignment of the entire semester for this survey class, in which the vast majority were not history majors-engagement with a primary source. Atypical for an intro level course of that nature and certainly atypical in terms of how a lot of these bigger, bigger, bigger survey classes are designed just because of the challenge that teaching primary sources poses.

Despite such examples, instructors still noted the difficulty (and in the preceding case, the rarity) of including physical primary source engagements in larger courses, clearly pointing to a concerted need to better support this kind of teaching. Digital resources may hold special promise here as one of their main strengths is circumventing problems of time and, especially, space. Few instructors expressed interest in or knowledge of the potential of these resources, at least in relation to supporting their pedagogy for larger classes. Better awareness of new tools and how they can be integrated into larger courses to support engagements with digital primary materials, may be an especially productive avenue to explore.

\section{Course Design: Teaching with Primary Sources in Smaller Courses}

When instructors described the courses in which primary sources play a central role, they most often referred to their smaller courses, either upper division classes for majors, or smaller introductory seminars. Given the smaller number of students and the often more focused topic of the courses, instructors were often able to design their courses with substantive and sustained engagements with primary sources. With these deeper engagements learning goals also shifted, becoming more focused to include not just the attainment of essential critical thinking skills (though this was still a stated goal of advanced courses), but also disciplinary knowledge, approaches, and techniques. Not infrequently in the sampled transcripts, the creation of new knowledge through engagement with primary sources was a major course objective, either through substantive research projects or the creation of physical or digital exhibits using archival, special collections, or museum materials.

When designing smaller courses, instructors approached course design in two general ways. In the first case, they began with a specific topic and then tried to find sources to suit it. In the second, they began from the collections and built their course around the resource. Each of these models requires different levels of support from archivists, special collections librarians, and museum staff and are likely to use different kinds of institutional resources.

The first model, wherein instructors design their course around a topic and then find the sources, is perhaps more common as instructors are more likely to design courses around their research interests, and institutional physical collections may not be adequate to fully support their subject area. Nonetheless, primary sources are critical parts of their classes, and a majority of the sampled interviewees noted reaching out to library, archive, or museum staff at some 
point during course planning. However, such outreach tended to come towards the end of the process when the course was mostly set, leaving both instructor and collections staff to find appropriate materials either locally or through a third party resource. As one instructor described, "So I usually send them the syllabus, a kind of description of the class, whether it seems like an advanced class or really novices. So I guess that's mostly how I have communicated."

Conversely, instructors may build their course, or their course assignments, around a specific campus collection; as one instructor explained, "I feel like it's better to go the ground up of just, like, look at what we have [in on-campus collections] and then think about what ideas and concepts can be generated from what we have." The ability to design such a course is naturally constrained by the nature of the materials in the institution's collection and so may not be feasible for all instructors, though digital resources and tools may make this increasingly possible. For example, one instructor described the importance of finding digitally available, curated collections to plan their class around, "[What I need are] collections, documentary collections in different fields so that I don't have to go and find the materials myself. This does cause some problems. I mean I-if there aren't documentary collections in a given field, it's a real struggle to put a class together. But I look for those collections in order to start thinking about a new class." Another instructor described a hybrid approach, bringing in more digitized resources after students got initial exposure to their physical counterparts, "You know, we didn't really dig too deeply into these digitized manuscripts until we had had our first meeting. We had two meetings scheduled in Special Collections to look at some, like, actual physical objects, and so once we had had that meeting...then I started incorporating more of the manuscripts into the kind of day-to-day lesson plans." Courses organized in this way, especially when reliant on an institution's physical collections, requires much more extensive collaboration with collections' staff and likewise, relies much more heavily on the latter's knowledge of the collections. In the second case, course planning also requires a clear articulation of learning objectives and how physical and digital materials can be used to achieve different learning goals.

Archivists', special collections librarians', and museum staff's knowledge of their collections was described as critical to the success of courses relying heavily on locally held primary source collections. This is true for identifying the collections and sources to begin with, but also extends to planning assignments. Courses in which students are expected to research specific sources or parts of the collection can prove especially challenging to plan for. As one instructor noted, "I don't know how to plan a lesson around a mysterious object, you know, that has yet to be chosen by a student that I haven't met yet.” Instructors describe such projects as being especially engaging and valuable to students, but again, note this particular challenge, "I can see how exciting these projects are to them, I would have incorporated it more into the day-to-day syllabus, which is a little difficult to think about, because I don't know what the books are that they're researching." While few collections are completely knowable, and students' research interests hard to predict, staff knowledge of their collections could at least mitigate such perceived difficulties, provided they are engaged early in the course planning process.

Outreach and collaboration early in the course planning process is, therefore, essential to fully capitalize on staff knowledge, but most faculty described some uncertainty over how much lead 
time collections staff need, or at least, described a learning curve: "So, it's really kind of about me learning how much lead time they need, what are the possibilities and then making sure my expectations are in line with that." One instructor noted that it was important to be in contact early, as collections staff have a better understanding of what materials may and may not work for different exercises or lessons, "we're quite scrupulous about sort of being in touch early about which materials and often back and forth, "well, this material, we have it, but it might not work as well." When working with an institution's physical collections, designing effective courses requires much more communication and collaboration, as well as longer lead times, than instructors may be used to compared with other kinds of courses.

Collaboration, however, is especially important when teaching with primary sources. For example, team teaching, either with multiple instructors or instructors and archivists, librarians, and museum staff, was noted as being an especially effective approach to planning engagements around primary sources. The precise in-class dynamics will be discussed in greater detail below, but multiple instructors noted how team teaching expanded both the breadth and depth of their engagements with primary sources: "A way you can enhance your use of primary sources is by working with someone who has access to knowledge about how to work with a very different kind of set of primary sources." Another instructor further explained how team teaching affected both course planning and the actual running of the course: "it gives you somebody to bounce ideas off of in real-time, not only as you're developing but as you're going week to week in a course."

Such collaborations do not often happen instantaneously, however. Many instructors described how their relationship with archivists, special collections librarians, and museum staff has grown over the years: "I have very long and deep relationships with staff in Special Collections and at [the college museum]. And so there are certain patterns that we have developed over the years that allow us to do successful sessions." Such long term collaborations begin with a single instance of outreach, and while not every instructor will turn into long term collaborators, it is still important. As one instructor explained, "This was the first time a librarian actually reached out to me, because it hadn't happened before. I feel like before the two of you were here, I didn't know anyone. I don't know how long you've been here but...Before this, nobody kind of even registered that I was here." Another instructor recalled a similar experience, "I was also kind of staggered to realize...that I didn't particularly make use of repositories on campus. And I had no idea there was a strata of university employees who might want to help me in that enterprise."

\section{Course Design: Textbooks and Primary Sources}

Whether designing a syllabus for large or small classes, instructors repeatedly noted the centrality of primary sources in how they structured their courses. However, a few instructors went a step further and discussed how they relied on primary sources not just to achieve their learning objectives, but to overcome shortcomings they find in textbooks. Some instructors focused on the comparative strengths and weaknesses of textbooks as pedagogical tools, while others focused on growing concerns over their expense and saw primary source collections, held by their institution or available from third parties, as a way of ameliorating this issue. 
One instructor summed up the limitations they saw in textbooks succinctly: "Everybody thinks they're going to design the next perfect reader or the best textbook. And it may just be that everybody has their own vision of what they really-what sources they really need or what's really going to fit to a particular kind of lecturer." Because there is no one size fits all approach to teaching, textbooks lack the flexibility or adaptability that instructors desire. Many instructors may get around this by assigning course readers or sourcebooks that provide them with a greater range of primary sources to incorporate into their course. Indeed, most instructors noted that when using a textbook, they typically had to supplement it anyways, leading them to question the value of the textbook in the first place: as one said, "I started out using a textbook, and I was dissatisfied. I just found myself feeling dissatisfied because I had to supplement it anyway."

Instructors that used both textbooks and supplementary sourcebooks also noted that such supplements are not perfect fixes to the limitations of textbooks, however. Some instructors point to the absence of context when students encounter sources in such formats; as one instructor explained, "The Norton Anthology of English Literature-lots of universities teach this, it's kind of a standard textbook...but the whole point of my module is trying to say to them these primary sources weren't born in books like this." Other instructors noted that such source collections gloss over the constructed (and often biased) nature of knowledge, the historical record, and the canon, though some used these collections as an opportunity to discuss these very issues. For example, in one instance, an instructor had students compare the published, edited works of Emily Dickinson with the primary documents newly available from the open access Emily Dickinson Archive to great effect: "The students came in screaming. They were like this, you know, steam coming out. 'I can't believe he (Franklin) made that decision. I can't believe he-look at this.' So what it did was they felt comfortable enough to look at his version, his edited version and her manuscript version to say they're not the same, and then they didn't want to use Franklin anymore." ${ }^{17}$ As primary source collections become increasingly available digitally, such exercises may become increasingly an option for instructors frustrated with published textbooks and readers.

Beyond the pedagogical limitations of textbooks, some instructors also highlighted increasing concerns over their cost, and saw primary sources available through the library, either through its physical collections or digital subscriptions, as a way to remedy this growing cause for concern. One instructor summed up his thinking thusly,

The first two years that I taught this class, I used a textbook, the standard Northern Renaissance textbook that I had used as a student. I found that the students, probably most of them, didn't read it, it's quite expensive, and also I realized the way I teach the class it was totally unnecessary for them to read it...And so I thought, 'this is ridiculous!' it's like extra money for them. And so I decided to drop the textbook and have them read exclusively primary source texts that I selected to go with the lectures. Because I thought, that's something that I think was really lacking in the students' writing and their

\footnotetext{
17 The Emily Dickinson Archive, https://www.edickinson.org/.
} 
research is that they immediately go to secondary sources and don't hear the voice of the period.

Taking this action did, however, require a significant investment of labor. This instructor noted taking a whole summer to identify the sources they would use in place of the textbook. Here the library played a critical supporting role as the instructor noted they relied on the library to scan materials, place items on reserve, and perhaps most importantly, handle copyright issues. Used in this way, primary source collections resonate strongly with the growing movement behind the creation and adoption of open educational resources (OERs), and future work can elucidate the potential synergy between the two. Certainly, as instructors are already invested in using primary sources in their curriculum, they could serve as gateways to further OER use. At the very least, assisting instructors who want to move away from textbooks represents several opportunities for the library to increase its collaboration with instructors as they design and revise their courses, while simultaneously reducing textbook costs for students.

Though many instructors noted the importance of primary sources and their shift away from textbooks, there was some debate over the appropriate balance between primary and secondary sources. The instructor quoted at length above also noted this challenge, "I think the biggest challenge there is that I'm worried that I may have overcorrected in giving so much emphasis on primary sources that I'm not introducing them to important secondary kinds of material.” Many instructors noted their own preference for working with primary sources in that they brought them directly into contact with the time period under study, avoiding the interpretive filter provided by secondary materials. These instructors often went a step further in that they also believed their students shared the same preference. However, other instructors noted that a particular challenge with teaching with primary sources is that students often just want to know what the "correct" interpretation is, or "what it all means." Instructors must therefore balance students' initial frustration with the uncertainty of working with primary sources against the delayed benefits of developing critical skills. Indeed, some instructors related that working with primary sources was a good way of breaking students out of the desire for clear cut answers they can memorize and repeat on exams, as one instructor said, "Rare books need to be an opportunity for them to get out of that mode where there isn't a great way to get an A.”

Instructors further stress that they also need to provide enough basic information so that students are in a position to work constructively with primary sources to begin with. In the absence of textbooks, this onus falls solely on the instructor, who then must juggle this along with working with students on interpreting primary sources. While instructors often stressed the value of students engaging with primary sources to develop their own interpretations and arguments, many also noted the importance of exposing them to scholarly secondary sources as well, either to contrast students' own interpretations of a source, or to show them how a scholarly argument is constructed. Much like providing foundational knowledge, instructors also struggled with finding the proper balance in including scholarly literature into their curriculum.

Primary sources provide instructors a powerful way to shape their courses into achieving the learning objectives they wish to achieve and to tell the story they wish to tell. Beyond this, 
primary sources can provide a viable alternative to expensive textbooks, a matter of growing concern among both librarians and instructors. While using primary sources as supplements to or outright replacements for textbooks offers many advantages, it may also require a significant investment of labor by the instructor, at least initially. Archivists, librarians, and museum staff can use their knowledge of their institution's collections, both physical and digital, to substantively support instructors in making this shift, simultaneously embedding the library, its collections, services, and staff, into the structure of the course.

\section{Course Design: Conclusions}

Instructors rely on primary sources as foundational elements of their course design and pedagogy. Despite this fact, instructors rarely have explicit training on how to teach effectively with primary sources and typically refine their course design and pedagogy over several years of trial and error. Likewise, instructors encounter numerous challenges when designing courses around primary source resources, especially when trying to incorporate substantive engagements with primary sources in larger classes. These challenges nonetheless present significant opportunities for archivists, librarians, and museum staff to collaborate with instructors. Indeed, many instructors are already accustomed to collaborating with collections staff around teaching with primary sources in some capacity, thereby providing a starting point from which collaboration can expand.

Instructors are also increasingly interested in using primary sources as a supplement or even a wholesale alternative to traditional textbooks, citing their customizability and reduced cost to students. However, instructors also struggle with finding the appropriate balance between primary sources and secondary sources, as students need experience working with a variety of materials. A move away from traditional textbooks and towards primary sources would increase the importance of institutional collections, both those held locally as well as those provided digitally by third parties. Such a shift would also increase the importance of collaboration, as instructors need increased support with source discovery, access, and copyright, and encourages collections staff involvement early in the course planning process.

Whether primary sources are built into the "DNA" of a course or incorporated as a special oneoff experience, instructors highly value their ability to teach with them. Yet designing a course is only half the battle, and even the best laid plans can go awry. The following section, therefore, zooms in on teaching with primary sources in the classroom, it explores how teaching with primary sources happens in practice and explores the challenges faced by instructors, students, and collections staff in executing effective engagements. 


\section{In the Archives-On the Screen: Teaching and Learning with Primary Sources}

Equally important to designing a course is how the course is actually taught in the classroom, for it is here that grand designs and lofty goals meet the limitations of the real world. When discussing how they taught with primary sources in practice and the challenges they faced therein, instructors highlighted several related themes. First was the issue of access and how various formats, and various spaces, encouraged or limited student engagement. Second, instructors reflected on the importance of parsing the medium and the message when teaching with primary sources and how different kinds of resources lent themselves to different pedagogical approaches and goals. Finally, though instructors face several challenges teaching with primary sources, the potential of new tools and new technologies has yet to be fully realized.

\section{Enchanting and Demystifying: Engaging Students with Primary Sources}

Instructors repeatedly stressed how primary sources drove increased student interest in and engagement with the subject of the course. Many instructors noted the almost talismanic power of (physical) primary sources to attract their students' fascination. The numinous quality of such materials is one of their greatest values as pedagogical tools; however, some instructors noted how this same quality of primary sources, as well as the somewhat hallowed aura of the spaces that hold them, also presents challenges. As archives, libraries, and museums continue to serve an increasingly diverse student body, who their spaces are for, who feels welcome in them, and who their collections represent, have become increasingly urgent areas of discussion. Instructors are likewise increasingly attuned to how their students perceive these spaces and the stories their students are interested in exploring.

While the materials held in archives, special collections, and museums may hold a special fascination, awe is seldom a learning objective. Rather, instructors want their students to use these objects to develop critical skills and be exposed to different perspectives, to think of primary sources as a method of inquiry, rather than just fascinating objects. While awe may come on its own, the skills needed to meaningfully engage with them do not. Many instructors, however, viewed the former as a way to achieve the latter, as one instructor explained, "Exposure, exposure, exposure. They need to bring the students in early on in the semester, get their feet wet, get them accustomed to thinking in these terms, and it blows their minds the first time around like, 'What? It's that old?'” While instructors may rely on this kind of novelty or shock value to get their students engaged, many instructors noted that they have ultimately found this unnecessary, as one explained, "I think that I was kind of relying on what we might call as a shock value, right, the novelty value. And what I think I learned in doing it was they don't need novelty value or shock value to really find these materials enthralling."

Though students may find primary sources innately enthralling, instructors noted that part of their job was to move students beyond this superficial level of engagement into a deeper level of 
analysis. One instructor explained the arc of their approach to teaching with primary sources this way, "A lot of the job, in a way, is to enchant them and then they find out that it's not so enchanted. It's actually really complicated and historical." This process of disenchantment can also benefit students who may find working with such materials intimidating, moving them past the awe and fear of handling the materials and into a mode of inquiry and analysis. Through this process, instructors can also develop learning objectives beyond simple exposure through the encounter and achieve deeper "mastery" wherein students are able to think critically and historically, empathize with diverse perspectives, and evaluate quality and relevance. ${ }^{18}$ Achieving this goal is not always easy, especially in short one-off sessions, and instructors also expressed reluctance to sacrifice valuable class time for primary sources used as mere props or "fluff," as one instructor explained, “There's a very nice small collection of Renaissance materials here, I don't end up using them in my regular early modern literature course, primarily because I would use them in a kind of show and tell fashion; it doesn't seem worth it." While primary sources can be powerful drivers of student engagement, it is not enough if they remain mere curios.

Getting students to meaningfully engage with primary sources need not rely solely on their mystique either. Instructors noted other ways in which primary sources could drive student engagement, one of the most prominent, at least for more advanced courses, being the ability to work with materials that had not previously been studied, as one instructor explained,

I would say, 'Nobody, for the most part, has worked on this, so you are the first person to have the opportunity to compare these two books, which exist in no other place in the world, the first person to be a scholar of these two books and to come up with ideas and observations about them,' is incredibly emancipating for young people. It's like, 'Wow. I get to actually do something that hasn't been done before.'

The opportunity to work with such materials allows students to become researchers and experts in their own right, while also moving them away from their focus on learning the "correct" interpretation or right answer.

Likewise, many instructors remarked upon the value of the university archives in getting students to engage with primary sources, as one instructor observed, "Students get very enthusiastic about researching their own school." Instructors described utilizing the university archives to explore topics ranging from urban development and environmental policy, to social and racial justice. ${ }^{19}$ By using the university archives as a lens to investigate a wide range of issues, students are able to see themselves in the archives, exploring issues through the perspectives of people who once walked in their shoes. The ability for students to see themselves in the archives is directly related to larger concerns regarding representation in institutional

\footnotetext{
${ }^{18}$ See a fuller discussion in Elizabeth Yakel, "Teaching with Primary Sources: Past Present Future," in Teaching Undergraduates with Archives, eds. Nancy Bartlett, Elizabeth Gadelha, and Cinda Nofziger (Ann Arbor, Michigan: Maize Books, 2019), pp. 279-294, https://doi.org/10.3998/mpub.11499242.

${ }^{19}$ University archives have been at the foundation of several undergraduate research seminars focused on exploring the entanglement between slavery and university campuses. For several examples, see Sindy Lopez, "Higher Ed's Reckoning with Slavery," Ithaka S+R, January 26, 2021, https://sr.ithaka.org/blog/higher-eds-reckoning-with-slavery/.
} 
collections and perceptions of who belongs in these spaces, issues that instructors seem to be increasingly aware of.

A number of instructors remarked upon the extent to which their students seemed to be intimidated by or uncomfortable in collections spaces. As one instructor explained, the entire process of going into archives and special collections to look at materials can be daunting to students, "I mean it's intimidating as hell. If you've never done it before, it's really intimidating." This is compounded by the elevated aura often attributed to institutions like archives and museums. As another instructor said, "in students' minds it has this idea of a great seriousness, gravitas." The strict policies and procedures surrounding access, combined with the earnest atmosphere of these spaces, can make students feel like these spaces are not for them, that they are not serious enough scholars to be welcome in such spaces.

\section{The strict policies and procedures surrounding access, combined with the earnest atmosphere of these spaces, can make students feel like these spaces are not for them, that they are not serious enough scholars to be welcome in such spaces.}

Instructors did not identify a singular solution to overcoming this problem, but did stress the importance of repeated experience in and exposure to collections and collections' spaces. Collections staff can also play a critical role by providing outreach and demystifying the materials and spaces under their care. Ultimately, instructors described a process of learning and socialization that has to happen before many students feel as though they belong in and have real access to these spaces.

\section{Engaging with Primary Sources: Working with Physical Collections}

Instructors articulated many kinds and levels of engagement with primary sources in their teaching. This section focuses on the engagements, activities, and exercises instructors carry out in their courses, synthesizing common approaches and challenges. While the larger goal of inculcating the use of primary sources as a means of scholarly inquiry has been discussed above, this section explores how instructors rely on both the physical, artifactual nature of primary sources as well as content they contain (e.g. in the case of manuscripts) to achieve their learning objectives.

Many instructors noted the value of having their students work with physical collections when possible, and some considered the exercise to be increasingly important as their students lead increasingly digital lives. Exploring the physicality of a primary source, its materials, construction, degradation, preservation, feel, smell, etc., was frequently noted as an important pedagogical exercise and learning objective. Instructors expressed a variety of reasons as to why this was so important. First, the process of analyzing the source as an artifact helped to demystify it and shift students from a sense of awe into a mode of analysis (as one instructor said, "not just, 'this is very cool,' but why is this cool."). Second, this kind of artifactual analysis 
was often seen as a useful way to get students talking in class as they do not necessarily need any prior knowledge about time period or subject matter, they only need to examine what they see in front of them. One instructor rehearsed the standard questions they ask this way, "We'll just go through it together and say, 'What do you see here? What is this thing in front of you? What can you divine about who it was made for? What is its purpose? Who was, perhaps, its audience? Is there any evidence of its use? Was it handsomely bound? Is it illustrated? Was it expensive?' all those things." While some students may be more experienced than others in this kind of analysis, approaching primary sources in this way nonetheless helps to level the playing field in classes that have a mix of student knowledge and ability-a frequent challenge for instructors. Finally, this kind of analysis allowed students to develop new analytical skills, for while many students may have experience working with textual sources, working with and studying objects may be comparatively novel. The same may even be the case for some instructors, and is one place where collections staff's expertise in the objects under their care can be especially valuable in the classroom.

As the questions posed by the instructor above demonstrate, the physical qualities of primary sources are useful not just to help students understand what they are looking at, but can be used to anchor wider discussions about culture and society. However, some instructors noted that students can struggle in making this leap. One of the great values instructors saw in working with manuscripts and archival sources is that it can bring students close to the people of the past, encouraging empathy and leading them away from presentist thinking. While this may be a straightforward experience when working with the original notes of Emily Dickinson (to return to the example given above), it can be more difficult to replicate this feeling of immediacy when working with non-textual materials, or even textual materials where the author is unknown or in a language students cannot read. A common way of addressing this problem was to ask students to create "object biographies," examining the life of an object from its facture to its winding up in the institution's collection, as one instructor explained, "I think that's engaging for them, that kind of helps them think about people instead of just objects, which is another objective of that assignment."

A focus on the material qualities of an object prioritizes having students in the archive, special collections room, or museum to physically engage with the object. Managing students in collections spaces presented its own problems however, and some instructors noted this was the principal challenge they had when working with these kinds of primary sources. Instructors explained that they struggled with managing students in these often small spaces, and some noted that they capped their class sizes specifically to accommodate teaching in these spaces even if there was greater demand, as one recalled, "In the end it was mostly about how to get everything in there and how to manage a class size that big when you want people to have this hands-on at the museum, for example. Or even at the special collections, where you can fit 25. In fact, the room was designed for it, which is why we chose the number 25." Maximum occupancy does not, however, necessarily coincide with what is feasible for meaningful engagement with materials, or how many materials can or should be made available given the space and number of students, as the instructor went on, "But, you know, if you want everyone huddling around a manuscript, how do you do that? And so thinking logistically about how many items we needed 
available for a class session, those were the kinds of challenges that we struggled with all through."

Most instructors recalled relying on some form of group work to allow students to engage with primary sources directly, but struggled with balancing the time allotted to group work with that dedicated to a larger discussion with the entire class. Group work also typically requires the instructor to circulate to the groups to provide insight or direction, and this can also be a challenge, though one where instructors particularly noted the value of collections staff. While instructors noted a litany of related minor struggles and frustrations, generally, these pointed to the fact that classes held in collections spaces typically need to be much more planned and stage managed than regular class sessions. Here, input from collections staff can be especially helpful given their more extensive knowledge and experience of teaching in these spaces.

There is, of course, a limit to how planned and managed a class can be, and some instructors preferred an element of surprise or unpredictability in their sessions focusing on primary sources, thus one instructor noted of his classes, "It's a little bit like being in a band, maybe a jazz group or something improvisational, where if you play with the same musicians enough...they may not know [what you are going to do], but they know what your tendencies are and they fill in. And I find that that's the most exciting way for a class session to develop." As this instructor stressed, such a format works best with years of collaboration between them and the collections staff. Though not necessarily to the extent of the foregoing example, many instructors commented on the improvisational element of teaching with primary sources, citing the unpredictability of student questions, responses, and reference points, as well as the unknowability of what students might find in the collections if tasked with discovering sources on their own. As one instructor explained when discussing guiding students to use the archives, "It was very hard to calculate in the very beginning how undergraduates with very little experience working in the archives could find a chance of success. We tried some things that didn't work, and we found some things that did work." While most instructors understood these challenges to be a natural part of working with primary source collections, and not necessarily bad in and of themselves, some did worry that improvisation, if unsuccessful, reflected badly on the class, "I'm embarrassed too, you know, because I want it to go well, then it looks like it's kind of slapdash because you can't plan the whole thing out."

\section{Engaging with Primary Sources: Decoding Content}

While instructors find it critical to discuss the physical, material dimensions of primary sources, in many cases, their decision to include these materials in their courses was based not on their physical qualities, but on the content they contained. Indeed, a focus on content sometimes led instructors to prefer formats that made content more accessible, by modernizing fonts and spellings in printed or edited editions, for example. This is especially true for rare books and manuscripts, but can extend to works of art and other cultural materials as well. Instructors noted further challenges in teaching with primary sources when focusing on the content of a source, especially as such a focus lends itself more readily to working with digital surrogates and tools. 
Perhaps the most obvious challenge instructors face when teaching with rare books and manuscripts is the issue of language and paleography. Undergrads rarely have command of the languages primary sources are written in, and paleography and scribal shorthand pose a further challenge. Some instructors noted this was particularly vexing for their teaching, with one instructor explaining, "And this is the main hurdle. I mean, I can't use Japanese in my teaching. So you have to imagine using primary sources that are not in the language [from] where the primary sources are produced." Even materials in English can pose challenges, however, as one instructor noted, "it's in pre-1900 material that students find it quite challenging and difficult because of cultural, historical, and language differences...if you know the English language of the 1590 s or the 1670 s it is very different to that now and they often-so there's often quite hurdle there."

As this was an overwhelmingly common challenge, instructors expressed several ways in which they tried to circumvent this issue to be able to get at the actual content of the source. In some cases, instructors relied on students who did have knowledge of the source language to help guide their peers. This was, of course, most common in courses dealing with primary sources in modern languages, but some instructors similarly relied on students who had previous experience with ancient languages or paleography. Instructors valued the ability to encourage this kind of peer learning in their classes as it allowed students to take more ownership over their learning.

The most common approach to this problem, however, was to focus on visual materials and texts with significant visual content, "I tend to focus on heavily-illustrated material in rare books because it's just something that everyone can relate to, regardless of their backgrounds." Some instructors said that they found it fruitful to have their students compare and contrast the images with the text, its content, or simply its appearance on the page. Instructors found it fruitful to focus on the interplay between text and image and also explore how the methods used to analyze each could overlap or be interchangeable, as one instructor explained,

Most of the people that are in the course don't know the languages, so they basically gravitated towards images that have lots of painting in it. So initially they have a reaction of the painting, 'Oh yeah, I understand this.' Then we start talking, 'Well, where did the painting come from and what is it actually doing and why is it so complicated? What is it copying?' Then they start to realize, 'Oh my goodness, there's all kinds of depth. Reading the painting is no easy matter either.' What we're trying to do is almost, like, making them look at texts like a painting and painting like a text.

The importance of images in how instructors teach with primary sources naturally impacts their choice of sources to use and, as discussed above, finding sources with the right amount of visual material is a significant discovery problem. Given the limitations of catalog entries and metadata, instructors must either invest significant time in searching for the best materials, or rely on collections staff's knowledge of the collection.

Though digital tools could, conceivably, assist instructors teaching with sources not in English, for example by allowing annotations, few instructors spoke of using such resources in their 
teaching. By far the most common "tool" used to help students engage with and analyze primary sources was the ability to zoom in and magnify parts of texts, especially when dealing with challenging paleography, as one instructor said "It's a lot easier nowadays to show something on a big screen and even to be able to examine it more closely, more carefully, blowing it up. It's helped, it's done wonders with paleography and whatnot, but there's still no substitute for the smell in the book." Transcription was also a common exercise used by instructors to get their students to more closely engage with primary sources, and in some cases, utilized digital tools to assist. One instructor described working with the archives to digitize a few key manuscripts and loading them onto a transcription platform for students to "crowdsource" the transcriptions. In this case, the students were not only developing a deeper familiarity with the primary source, but were actively engaged in building a digital resource that could be used in the future, as the instructor explained, "farther down the road we can make them available through the library and another way."

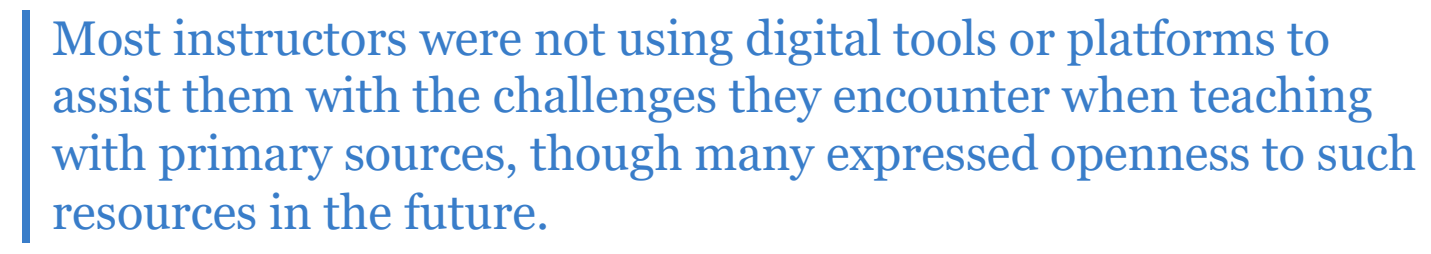

Despite such examples, most instructors were not using digital tools or platforms to assist them with the challenges they encounter when teaching with primary sources, though many expressed openness to such resources in the future, "I would in the future like to see how I could get a bit more involved in like more of the digital tools and things in my courses, all my courses actually." As the research for this project was conducted prior to the COVID-19 pandemic, it seems likely that interest in such tools has grown as a result of the shift to remote learning, though more research is needed to understand any shift in interests and priorities.

\section{Engaging with Primary Sources: Digitized and Digital Materials}

Focus thus far has been on how instructors teach with the physical materials housed at their institutions, yet the ever-growing availability of primary source materials through digitization has transformed the ways in which instructors incorporate primary sources into their courses. Though instructors noted that there was no substitute for the materials held in archives, special collections, and museums, it is important to highlight that they generally did not see digital resources as being inferior per se. ${ }^{20}$ Rather, instructors highlighted the different strengths and drawbacks of physical and digital primary sources, and the different roles these resources play in their teaching.

A consistent challenge expressed in the interview sample was the impossibility of local collections to serve the entirety of the subjects instructors teach. Because no collection can be

\footnotetext{
${ }^{20}$ Recent research has emphasized that student engagement with digitized primary sources is comparable to engagement with physical primary sources if the purpose of instruction is primarily focused on rhetorical analysis of primary sources. See Meggan Press and Meg Meiman, "Comparing the Impact of Physical and Digitized Primary Sources on Student Engagement," portal: Libraries and the Academy 21:1 (2021): 99-112.
} 
truly encyclopedic, digital resources are crucial, even in courses centered around an institutional collection. As one instructor explained of his course, "It's very open because, as the end of the day, you don't want them to just focus on what we have, but also to focus on what they're interested in." The growing quantity of digital resources has allowed instructors to rely more heavily on primary sources in the normal course of their teaching, whether by including them in their lectures or assigning students to engage with them through course assignments.

Instructors also see value in digital resources as they allow or spark increased student engagement: "I think going to the archives is a valuable experience in itself, but I also think that they want to, I think they would use primary sources more if they had more access to them and what that means a lot of times is digital." Some instructors also noted that the hours kept by institutional collections did not match the hours students typically work, as one explained, "Archives are generally open from nine to five, and students are used to doing a lot of their work at night or on weekends. So that is where the digitized project is, I think, a really good solution to a structural problem with teaching in archives." The great strength of digital resources, therefore, is first and foremost the flexibility they afford, or viewed another way, the increased access they allow.

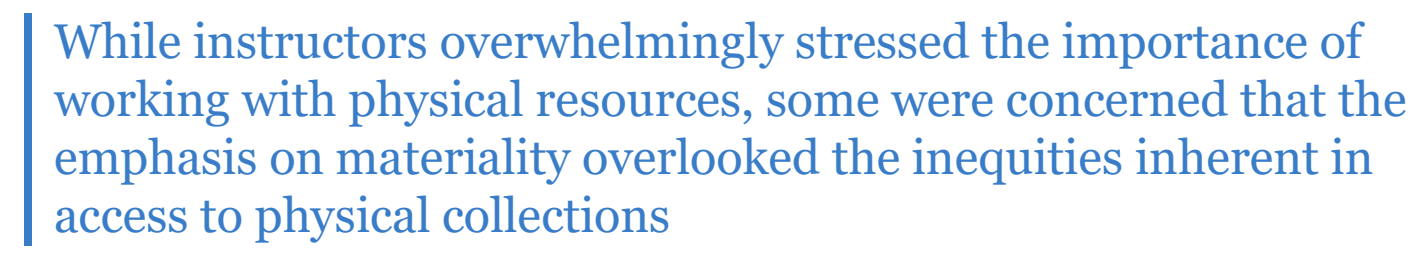

Digital access can serve as a powerful democratizing force that can empower both instructors and students, especially those at institutions without major physical collections, to teach and learn with primary sources. While instructors overwhelmingly stressed the importance of working with physical resources, some were concerned that the emphasis on materiality overlooked the inequities inherent in access to physical collections, as one instructor said, "I see a trend in my own discipline towards materiality and looking at primary sources, and my concern is just access." Instructors seem increasingly aware of this problem and noted how digital materials can open up avenues for themselves and for students who may not have the resources ever to travel to see collections in person, as one instructor explained, "I find that the museums have online or virtual exhibits. And that's again, a really wonderful resource for students who can't necessarily travel outside the country." In other cases, instructors recalled students who, after working with digital facsimiles of primary source materials, made it a special point to see these objects in person when they were able to travel on their own, and made sure to tell their instructor even after the class had ended.

While instructors highlighted the importance of digital materials in facilitating access, many noted that digitization of materials was uneven, and that such resources were not always available for the subjects they taught. One instructor explained, "For me the challenge is that we wouldn't actually have anything physical that they can look at. In which case the access to digital archives was really important." Others recounted how they relied on a handful of digital collections that were relevant to their teaching area, often made available through a specific 
digitization initiative at another institution or even by specific scholars. These collections tended to be framed around a specific author or niche subject matter, and the frequency with which instructors spoke about such collections highlights the importance of efforts to make individual collections of materials digitally available.

Instructors also noted that, just as access to physical collections can have its challenges, access to digital materials can also be problematic. Here instructors highlighted the importance of the library and the various resources to which it subscribes, "On the digital side...you have different challenges. You have the challenge of are these resources accessible? Do we have to have a subscription to them? How many of us can use it at once? How do we use it? Are we allowed to print from it?" On the other hand, some instructors focused on the open access content being made increasingly available by publishers and third parties, "But then ProQuest allows that a little bit more. And JSTOR opening up so many different options like now with there being so much open access stuff. So I think with the digital world, accessibility is just incredible."



As previously covered, instructors recalled only limited use of digital tools to help them teach with primary sources. Some did, however, note that digital formats better enabled them to manipulate the material, to zoom in as already mentioned, but also to creatively juxtapose materials as one instructor described, "[There is an] amazing collection in the UK of the Dunhuang Caves, which are these caves in western China that are the greatest treasure trove of early Chinese manuscripts that's ever been discovered, and they are slowly all being digitized. And so you can have these fragments and manipulate them on the screen and put them together in different ways." Such examples were comparatively rare, however, and it was notable that when asked how they typically distribute digitized materials, most noted that, when not directing students to the database itself, they typically distributed PDFs of the sources. The reliance on the PDF format suggests instructors are not engaging with digital primary sources as true digital objects but more as analogs to print. Likewise, they are not investing time in engaging with primary sources on platforms that might allow them to better access the full potential of digital materials, though some did express interest in the possibilities in "Things that are multi-institution, that span continents, that bring repositories together and that have some extra interactive toolset that isn't simply: Here's an image."

Instructors who did take advantage of digital tools and platforms for their teaching typically did so by designing student projects around them. Instructors described using Scalar, Voyant, JSTOR Text Analyzer, Gephi, Palladio, and Story Mapper, as well as having their students build WordPress sites or Wikis. While these platforms were only mentioned rarely in the data, Omeka was mentioned slightly more frequently, though some instructors noted the effort required to build their site: "My Omeka site looked really bad. I really thought it was very ugly. I couldn't get the things to line up properly...And I figured it out enough to be able to ask students to do this and to be able to do it with students. I keep thinking, I wonder if I should do it again this 
semester. Because it really was a little time consuming for students.” This latter point, the time and effort required of students, was another concern among instructors about using digital tools. In some cases, instructors did not have time to instruct their students in how to use the tool or platform, or in other cases struggled supervising student projects utilizing tools learned elsewhere, such as AutoCAD or GIS.

The full potential of digital primary sources has clearly yet to be exploited, however, as digital platforms and tools continue to be developed and refined, it will be helpful to keep in mind the various challenges and drawbacks instructors noted about digital sources. The most prominent challenge, unsurprisingly, is capturing the physical, sensorial aspect of primary sources in digital media, as one instructor noted, "It's one of the kind of upcoming issues. Like how do we include the sensory aspect of it in these digital kinds of surrogates?” Instructors were especially attentive to the issue of scale and how digital facsimiles of primary sources can often give a false sense of the size of the object. While scale may be a relatively easy problem to address, capturing other physical qualities, weight, mass, smell, feel, etc., will likely be more challenging.

\section{Instructors were especially attentive to the issue of scale and how digital facsimiles of primary sources can often give a false sense of the size of the object.}

Perhaps the most common failing of digital sources instructors noted was that digitization efforts often neglected to include important metadata or paratext, such as covers, frontispieces, ex libris, and so on, as one instructor pointed out, "They leave out quite a lot and they leave out very specifically stuff that comes at front of books, prefaces, dedications, commendations all these kind of-you know prefatory essays which are actually crucial in 17th Century in terms of the ways in which authors and printers and publishers are trying to set up their books." Others stressed the importance of being able to see bindings or examine spots of damage or wear, while still others noted the importance of being able to sense the quality of the materials and overall production.

Many instructors recounted how they turned these shortcomings into an important element of their pedagogy by highlighting the limits of digital media for students who are increasingly unaccustomed to non-digital formats. As one instructor explained, "I'm trying to have the students leave with an appreciation of when they encounter things in the digital, they're always mediated in some way and there's things that are lost...if I scan in a book and I see it online, it is different than the book that I hold in my hand, because for them, they think those are just analogs to one another, and they're not." Many instructors noted that they used digital sources as an opportunity to reflect on the construction of the historical record, and interrogate the choices made (and who makes them) about preservation and, of course, digitization, with one noting, "When you digitize stuff, you're never going to capture everything, but what the digitization process allows you to do is to highlight specific things."

The ability to "highlight specific things" is perhaps the basic tenet of teaching with both physical and digital primary sources and neither is a substitute for the other. Rather access to both kinds 
of resources has allowed instructors to expand their use of primary source materials in their teaching, and offered new, more accessible avenues for their students to engage with primary sources. While digitization efforts have transformed access to these materials, it is clear that their full potential in transforming pedagogy has yet to be realized.

\section{Conclusions}

Teaching with primary sources is a matter of central concern to many instructors in the humanities and humanistic social sciences and is a major focus in the library, archive, and museum professions. Perhaps more so than in other domains of research and pedagogy, primary sources encourage, and often require, close collaboration between instructors and collections staff, though the exact nature of these collaborations vary widely. To aid librarians, archivists, and museum professionals in developing stronger collaborations with the instructors on their campuses, this report has highlighted the challenges instructors face in discovering, planning courses around, and teaching with primary sources. Based on these findings, we conclude with a discussion of several leitmotifs that have surfaced throughout the report and that may warrant special consideration by all those who support teaching with primary sources.

\section{Teaching Students to Fish}

Despite great enthusiasm for teaching with primary sources, and for having students learn with primary sources, instructors generally struggle in finding the proper balance between providing guidance and direction on the one hand, and allowing students to discover and engage with materials on their own. Perhaps the most obvious solution is a scaffolding approach, whereby students are given increasing freedom and less direction in finding primary sources. Ideally, scaffolding would occur at two levels, first within individual courses and at the departmental level, so that skills are built up over the arc of the student's education. While some instructors noted that their departments had had some discussions of teaching things like critical thinking and information literacy, there typically seemed to be little coordination in how individual courses might build upon each other or familiarize students with key resources over the course of a major.

Developing a scaffolded approach may be especially important in developing student discovery skills. Doing so will, of course, require significant coordination and collaboration with and between instructors. However, the library can leverage its centralized position on campus to facilitate such work. Furthermore, many instructors noted bringing in librarians and archivists for "one-shot" library sessions on the library's databases and other services, and so already see the library as a partner in this kind of instruction. Indeed, some instructors pointed out how the library is actually central in directing their research and their teaching, as one instructor expressed, "Libraries aren’t passive agents of information, right?... A library shapes your research because of your access to things, and librarians shape your research because of their knowledge of the collection." Helping students understand this fact is a critical step towards improving their discovery practices as well as instructors' confidence in their students' ability to discover primary sources independently. 
Collecting organizations and third party vendors can also play a significant role here, and there is much that can be gained by creating thoughtful collections designed with an eye for instruction rather than pure research. Indeed, as instructors made abundantly clear, it is important to take a holistic approach that recognizes how teaching and research are interconnected. Creating such collections may be a significant challenge for libraries, archives, and special collections, as well as third party vendors, however. Instructors are likely to have differing needs in balancing curation and openness depending on class level, size, and instructors' specific learning objectives. Libraries, archives, special collections, and museums may hold an advantageous position in so far as they know the teaching and research strengths of their faculty, can customize accordingly, and potentially develop such sandboxes as a regular service. Because no institution's archives and special collections can speak to the whole range of instructors' teaching areas, third party vendors have an equally important and complementary role to play.

\section{Physical versus Digital or Physical and Digital?}

Unsurprisingly, the format of primary sources, i.e. physical or digital, emerged as a major issue of consideration throughout the entirety of instructors' practices in teaching with primary sources. While library and archive professionals have focused much of their work and outreach on engaging instructors and students with physical collections, it is important to highlight that instructors held a great diversity of views on the relative values of physical and digital resources. Perhaps most significant was that, while instructors highlighted the importance and special value of working with physical materials, they did not in turn assert that digital materials were inherently inferior or "less than" their physical counterparts. Rather, instructors recognize that physical and digital materials each have their specific strengths and utility in their courses, and suggests the too often oppositional framing of physical versus digital needs to be reconceived in a "both/and" framework. ${ }^{21}$

Instructors look to digital resources, for example, for their breadth and flexibility, noting in particular that students are more likely to utilize resources they can access immediately and at any time. On the other hand, most instructors noted the special, numinous quality of physical sources and the material qualities of objects that cannot be replicated by digital means. Perhaps some of the most interesting discussions of the issue of format was from instructors who utilized both by relying on physical resources as a starting point and then allowing their students to explore digital resources as their interests dictated. How physical and digital resources can be used in tandem and build upon each other is an issue to explore in future research.

Finally, the profession's focus on materiality and in person engagements must be balanced by considerations of access, and much as collecting institutions are rethinking who is represented in their collections and welcome in their physical spaces, they should also consider who teaching with primary sources is for in the first place. As some instructors noted, the emphasis on physical primary sources can shut out instructors and students at small or less wealthy

\footnotetext{
${ }^{21}$ For more on this issue in the literature see Meggan Press and Meg Meiman, "Comparing the Impact of Physical and Digitized Primary Sources on Student Engagement," portal: Libraries and the Academy 21:1 (2021): 99-112.
} 
institutions, as well as instructors whose employment is contingent. Developing and strengthening the practices and literature surrounding digital primary source pedagogy is thus a matter of equity, and deserving of greater attention. The COVID-19 pandemic has, of course, drastically refocused attention on remote learning and the potential of digital resources. It remains to be seen, however, if the attention given to digital sources and engagements will outlast the pandemic and if the lessons learned during will increase engagements with new audiences, though there are some signs that it will. ${ }^{22}$

\section{Collaboration}

Teaching with primary sources is one of the most collaborative classroom endeavors. Throughout their discovery, course design, and in-class practices, instructors described the importance of working with librarians, archivists, and museum staff, and many noted the value of these enduring relationships, some decades long. Effective collaboration can take on many forms, and especially when it comes to teaching with primary sources, was heavily dependent upon the role primary sources were made to play in the class.

Collaboration was most intense in courses designed around specific physical collections. In these cases, instructors relied on collections staff's superior knowledge of the archive or special collection and were especially important in helping guide and support student projects. In other cases, such as in single "show and tell" sessions, instructors noted relying on their colleagues' experience teaching with these kinds of physical sources and their knowledge of book history in cases where instructors themselves were not well versed. Whether collaboration took the form of an entire course hosted in the archives or a single session spent looking at a manuscript, a hallmark of success was both instructors and collection staff having a clear understanding of each other's domain of expertise and achieving the appropriate balance between them in the classroom.

\section{Teaching with Primary Sources: Post-COVID Futures}

The research for this project was conducted prior to the onset of the COVID-19 pandemic and the massive, sudden shift to remote learning. Given the emphasis on materiality and the thrill of the "encounter" in much of the pedagogy surrounding teaching with primary sources, this shift has profoundly impacted both instructors and collections staff. Ithaka $\mathrm{S}+\mathrm{R}$ is undertaking further research to better understand how instructors who teach with cultural materials like primary sources made this transition, but it is worth considering here what the principal issues and trends from the status quo ante might look like on the other side of the pandemic.

This issue of format, physical or digital, immediately rises to the surface as normally in-person class sessions in archives and special collections had to be adapted to remote learning. It will be interesting to see if this shift has encouraged instructors to experiment more with digital resources and tools and if this will continue post-pandemic. Alternatively, it may be that, if

\footnotetext{
${ }^{22}$ See for example Melinda McPeek, Jennifer Piegols, and lan Post, "Reconceptualizing the Classroom: An Immersive Digital Primary Source Exercise During COVID-19," Museum and Society 18:3 (2020): 337-40, https://doi.org/10.29311/mas.v18i3.3534.
} 
"absence makes the heart grow fonder," the importance of physical collections and the benefits of working in collections spaces has become more clear and leads to increased engagement and sharper pedagogical goals when teaching with physical resources. Indeed, it would seem likely that the constraints of the pandemic have clarified the specific strengths and limitations of various formats, platforms, and technologies. As institutions consider the various possible futures of teaching with primary sources post-COVID, it will be important to understand what lessons have been learned and how instructors will adapt their teaching in response.

Despite the isolation and separation of life under lockdown, archivists, librarians, and museum professionals have also displayed a tremendous amount of energy and interest in collaborating and sharing information and experience. Strategies for remote engagement and working with new tools have become common topics of discussion across the organizations that support teaching with primary sources and their various listservs, for example. It is less clear, however, how the lines of communication and collaboration with instructors have been maintained throughout the pandemic. As instructors worked essentially in crisis mode throughout the Spring and Fall of 2020, it would not be surprising if these relationships have suffered, even for instructors with years long histories of collaboration with collections staff. It is fortunate that archivists, librarians, and museum staff have traditionally invested so much in outreach, as this will likely be critical in reengaging instructors who may have abandoned teaching with primary sources during the pandemic.

In light of the historic disruption caused by COVID-19, there may also be opportunity to work with faculty in new ways. Our findings suggest that the most successful engagements with primary sources occur when instructors are building their courses with sources or collections in mind (rather than designing their syllabus and then seeing what sources are out there that could match). As many instructors are likely to be redesigning or updating syllabi post COVID-19 and the protests for racial justice following the murder of George Floyd, the time is ripe to support instructors as they reimagine their courses. Primary sources are a nexus of teaching, research, and collection development; consequently, efforts to advance equity, inclusion, and respect for fact in one reinforces efforts and creates new opportunities in the others. As the world emerges from lockdown and begins to grapple with hard truths revealed over the preceding year, the primary source, serving as both evidence and witness, will be even more critical in shaping the ways we teach and explain the world around us. 


\section{Recommendations}

In the sections below, we provide recommendations for those who support teaching with primary sources-libraries, archives, special collections, and museums, publishers and vendors, societies, and instructors themselves.

\section{Working with Collections}

\section{Libraries, Archives, Special Collections, Museums}

- Consider the teaching needs of instructors when setting digitization priorities. Instructors recognize the value of these efforts but note that emphasis is typically placed on textual materials as opposed to objects, paraphernalia, audio recordings, and images.

- Collaborate closely with faculty to ensure that learning objectives are clearly defined and take learning objectives into account when deciding on digitization priorities.

- Instructors rely on collections staff knowledge of the materials under their care. Collections staff should leverage this to suggest alternative strategies to achieve learning objectives when appropriate.

- Both students and researchers are increasingly focused on finding marginalized voices in collections. Continue efforts to diversify collections and highlight opportunities for instructors to use such collections in their teaching.

- As an aspect of diversifying collections, make discussion of how collections form, how memory is constructed, and how different narratives survive or not standard elements of all instruction in collections spaces or provided by collections staff.

- Given the increased complexity and cost of digitizing non-textual materials, explore partnerships with third parties that may be better positioned to support such efforts.

- Instructors generally feel ill-equipped to utilize digital tools in their teaching with primary sources. Target trainings and workshops around specific digital tools useful in the undergraduate classroom and identify instructors to partner with as co-leaders.

- Focus workshops around teaching with high demand collections or classes of materials such as newspaper collections and university archives.

- Instructors note that collections spaces are not always open when students are most likely to be able to take advantage of them. Explore reallocating hours to better match student work patterns.

- Engage with faculty so that they are effective advocates to library administrators and university leaders to fund these changes.

- Instructors also express concern over overburdening collections staff. Survey instructors to generate data over whether concerns over staff capacity limit their engagement with collections.

- Work towards centralized discovery of university special collections housed in different units (e.g., museums, anthropology collections, rare books, university archives) 


\section{Publishers and Vendors}

- While instructors are generally positive about the increase in primary sources available digitally, they struggle finding materials that are good for use in the classroom. When developing collections, consider teaching as a core use and/or explore the creation of primary source collections geared specifically for teaching and the development of teachingfocused "modules" within existing collections.

- Consider in particular how instructors develop their classes and assignments, e.g., by supplying guidance on read times for articles, themes/topics, examples of lesson plans.

- Broaden collections development strategies to include materials in diverse formats (e.g., audio/visual materials).

- Instructors want more from databases than just a collection of images. Incorporate digital tools to turn databases into learning environments.

- Explore synergies between primary and secondary materials. Instructors note that secondary literature is a major primary source discovery mechanism; explore how this process could be made more effective.

- Because language is a common barrier to teaching with primary sources, instructors often focus on images and image heavy texts. Prioritize such resources and focus on making images embedded in texts discoverable.

\section{Outreach and Collaboration}

\section{Libraries, Archives, Special Collections, Museums}

- The library, archive, and museum professions have placed great emphasis on faculty outreach. The data make clear that this has been effective but more is still needed. In particular, outreach should be targeted around specific needs and resources, taking into consideration:

- Instructors whose teaching could directly benefit from specific collections or resources.

- Junior instructors, graduate student instructors, or instructors new to campus.

- The unique concerns and needs of adjunct and contingent instructors who may prefer to work with specific types of materials. Open access collections may be especially important for instructors who teach across several institutions.

- Disciplinary traditions around teaching with primary sources. Historians, for example may feel they do not need support as this is central to their discipline while instructors in other disciplines may want more basic assistance.

- Primary sources drive student engagement and interest and so are of potential value to disciplines facing declining enrollments. 


\section{Publishers and Vendors}

- Teaching with primary sources is a topic of central interest to a wide range of stakeholders (e.g. archivists, librarians, museum professionals, and faculty). Work closely with stakeholders when developing collections, especially those focused around teaching.

- Instructors struggle with using primary sources substantively in large classes, but digital resources and tools can help facilitate more focused engagement at scale. Focus outreach on successful examples of how digitized primary sources can be effectively used in a variety of classes, especially large classes.

- Instructors and collections staff express concern over how third parties create curated collections. Incorporate transparency as a key element of database development and outreach.

\section{Societies}

- Help instructors find and share content by hosting syllabi exchanges, assignment banks, and teaching resources for instructors on their websites.

- Sponsor sessions, workshops, and panels at national and regional conferences dedicated to teaching with primary sources.

- Instructors report that colleagues are an essential means of finding primary sources and developing pedagogical practices around them: professional societies can use publications, conferences, listservs, and other means to create and foster communities of practice. This may be especially useful in disciplines in which teaching with primary sources is a relatively uncommon practice.

\section{Curriculum and Course Development}

\section{Libraries, Archives, Special Collections, Museums}

- Early intervention in the course design process is key. Highlight successful examples that showcase the advantages of designing courses around institutional collections.

- Exposure and basic literacies were the most commonly expressed learning objectives for teaching with primary sources. Work with instructors to develop strategies for deeper engagements with primary sources that move beyond exposure and basic literacy.

- Develop guides and/or discovery platforms for digital primary sources that can build upon institutional collections.

- Explore using course development grants and micro grants (potentially in collaboration with Centers for Teaching and Learning) specifically targeted at:

- Translating excerpts of core primary sources to help address the common hurdle of teaching with primary sources not in English.

- Designing courses or student research projects involving collections that include historically underrepresented or marginalized voices. 
- Instructors are increasingly concerned about the cost of textbooks and sourcebooks. Explore opportunities to help instructors redesign course readings around physical and digital primary sources.

\section{Instructors}

- Despite professions of pedagogical importance, instructors rarely systematically teach their students how to independently find and work with primary sources. Reconsider curriculum to chart a path that will teach students these skills. Consider how this can be accomplished both within individual classes as well as at the level of a major.

- Engage with collections staff early in the course development process and work with them to consider scaffolded approaches to working with primary sources that promote information literacy, command of search and discovery, and domain knowledge.

\section{Societies}

- Advocate for increased attention to preparing students to teach with primary sources in $\mathrm{PhD}$ and MLIS programs. 


\section{Appendix 1: Teams and Local Reports}

\section{Bowling Green State University}

Colleen Boff, Stefanie Hunker, David Lewis, and Michelle Sweetser, "Supporting Primary Source Instruction in the Undergraduate Classroom at Bowling Green State University: Summary

Findings," https://scholarworks.bgsu.edu/ul pub/61/.

\section{Brandeis University}

Chloe Gerson, Laura Hibbler, and Matthew Sheehy, “Teaching with Primary Sources: A Local Report by Brandeis University Library,"

https://brandeis.alma.exlibrisgroup.com/discovery/delivery/o1BRAND INST:ResearchReposit ory/12424317230001921.

\section{Brigham Young University}

J. Gordon Daines III, Matthew J. K. Hill, Maggie Kopp, and Dainan M. Skeem, "Supporting Teaching with Primary Sources at Brigham Young University: An Ithaka S+R Local Report," https://scholarsarchive.byu.edu/facpub/4180.

\section{Brown University}

Heather Cole, Sarah Evelyn, Patricia Figueroa, and Holly Snyder, "Strengthening Primary

Source Pedagogy and Engagement at Brown,"

https://repository.library.brown.edu/studio/item/bdr:1146389/.

\section{California State University, Northridge}

Liz Cheney, Jamie Johnson, and Nicole Shibata, "Supporting Teaching with Primary Sources at California State University, Northridge,” http://scholarworks.csun.edu/handle/10211.3/217424.

\section{Dartmouth College}

Daniel Abosso, Joshua Dacey, Myranda Fuentes, and Morgan Swan, "Supporting Teaching with Primary Sources at Dartmouth College: A Report coordinated by Ithaka S+R,” https://digitalcommons.dartmouth.edu/dlstaffpubs/29/.

\section{Illinois Wesleyan University}

Meg Miner, "Supporting Teaching with Primary Sources at Illinois Wesleyan University," https://digitalcommons.iwu.edu/ames scholarship/116. 


\section{Indiana University, Bloomington}

Maureen Maryanski and Carrie Schwier, "Supporting Teaching with Primary Sources at Indiana University: An Ithaka S+R Summary Report,” http://hdl.handle.net/2022/25876.

\section{Johns Hopkins University}

Margaret Burri, Heidi Herr, and Jessica Keyes, "Supporting Teaching with Primary Sources," https://jscholarship.library.jhu.edu/handle/1774.2/63241.

\section{Lafayette College}

Terese Heidenwolf and Lijuan $\mathrm{Xu}$, "Supporting Teaching with Primary Sources at Lafayette College,” http://hdl.handle.net/10385/g732d954s.

\section{Northern Michigan University}

Catherine Oliver and Marcus Robyns, "Teaching With Primary Sources: A Report for Ithaka S + R from Northern Michigan University,” https://commons.nmu.edu/facwork book/48/.

\section{Pennsylvania State University}

Steve Borrelli, Jennifer Meehan, Rebecca Miller Waltz, and Julie Porterfield, "Ithaka S+R:

Teaching with Primary Sources," https://pennstateoffice365-

my.sharepoint.com/:f:/g/personal/jmp48 psu edu/EqwAzyKf2oVPj-

8sV3oHjDwBZxvNZ13da3zwJ63zkDOeHQ.

\section{Princeton University}

Rebecca Friedman, Kelly Godfrey, Sara Logue, and Gabriel Swift, "Teaching with Primary Sources at Princeton University: A Summary Report," http://arks.princeton.edu/ark:/88435/pr1x231.

\section{ProQuest}

The research team at ProQuest interviewed instructors at Arkansas State University, Cambridge University, Florida International University, John Jay College, Mount Mercy University, Texas State University, University of Manchester, University of Maryland, University of Oklahoma, University of Redlands, University of Arkansas - Fort Smith, University of Cincinnati, and Winston Salem State University. Sarah Brennan, Andrew Laas, and Barbara Olson, "Teaching Undergraduate Students Using Primary Sources," https://webcache.brandmaker.com/2399 1602192897125.original.file. 


\section{Texas A\&M University}

Tina Budzise-Weaver, Joel D. Kitchens, and Kevin M. O'Sullivan, "Teaching with Primary Sources: Report From Texas A\&M University For Ithaka S+R,"

https://hdl.handle.net/1969.1/191016.

\section{University of Arizona}

Lisa Duncan, Mary Feeney, and Niamh Wallace, ““The Real 'Aha!' Moments”: Teaching

Undergraduate Students with Primary Sources,” http://hdl.handle.net/10150/642372.

\section{University of Illinois, Urbana-Champaign}

Cara Bertram, Cait Coker, Ruthann Miller, and Linda Stepp, "Ithaka S+R Study on Teaching with Primary Sources Local Report for the University of Illinois at Urbana-Champaign," http://hdl.handle.net/2142/107790.

\section{University of Kentucky}

Jay-Marie Bravent, Danielle Gabbard, Deirdre Scaggs, and Matthew Strandmark, "Teaching Undergraduates with Primary Sources 2020 Research Study Report,"

https://uknowledge.uky.edu/libraries reports/2/.

\section{University of Miami}

Shatha Baydoun, Christina Larson, and Roxane Pickens, "Supporting Teaching with Primary Sources at the University of Miami,"

https://scholarship.miami.edu/permalink/o1UOML INST/105q9vf/almag9103150538930297 $\underline{6}$.

\section{University of North Carolina, Chapel Hill}

Emily Kader, Sarah Morris, Jason Tomberlin, and Ashley Werlinich, "Teaching With Primary Sources at the University of North Carolina at Chapel Hill,"

https://cdr.lib.unc.edu/concern/articles/s1784v201.

\section{University of Pittsburgh}

Diana Dill, Carrie Donovan, Jeanann Haas, Berenika Webster, and Clare Withers, "Teaching with Primary Sources at the University of Pittsburgh Summary Report of Local Findings," http://d-scholarship.pitt.edu/39698/.

\section{University of Sheffield}

Peter Barr, Arantza Barrutia-Wood, and Catherine Bazela, "Supporting Teaching with Primary Sources," http://eprints.whiterose.ac.uk/166875/. 


\section{University of Southampton}

Katie Atkins, Eleonora Gandolfi, and Matt Phillips, "Supporting Undergraduate Teaching with Primary Sources," http://eprints.soton.ac.uk/id/eprint/444023.

\section{University of Virginia}

Krystal Appiah and Brenda Gunn, "Supporting Teaching with Primary Sources," https://doi.org/10.18130/v3-z8bd-eo97.

\section{Washington and Lee University}

Emily Cook and Paula Kiser, "Teaching with Primary Sources at Washington \& Lee University: Humanizing History and Engaging with the Topics of Today,"

https://dspace.wlu.edu/handle/11021/34876.

\section{Williams College}

Lisa Conathan, Lori DuBois, and Anne Peale, "Teaching with Primary Sources at Williams College: A Summary Report of the Ithaka S+R Teaching with Primary Sources Project," https://unbound.williams.edu/williamsarchives/islandora/object/libraryannualreports\%3A3.

\section{Yale University}

Melissa Grafe, David Hirsch, Bill Landis, and Sara Powell, "Support Services at Yale University for Teaching with Primary Sources: An Exploration of Instructor Rationales and Needs," https://elischolar.library.yale.edu/yul staff/13/. 


\section{Appendix 2: Supporting Teaching with Primary Sources Interview Guide}

\section{Background}

Briefly describe your experience teaching undergraduates. Examples: how long you've been teaching, what you currently teach, what types of courses (introductory lectures, advanced seminars) you teach

- How does your teaching relate to your current or past research?

\section{Training and Sharing Teaching Materials}

How did you learn how to teach undergraduates with primary sources? Examples: formal training, advice from colleagues or other staff, trial and error

- Do you use any syllabi, assignment plans, collections of sources, or other instructional resources that you received from others?

- Do you make your own syllabi, assignment plans, collections of sources, or other instructional resources available to others? If so, how? If not, why not?

\section{Course Design}

I'd like you to think of a specific course in which you teach with primary sources that we can discuss in greater detail.

- Do you have a syllabus you're willing to show me? I will not share or reproduce this except for research purposes.

- Tell me a bit about the course. Examples: pedagogical aims, why you developed it, how it has evolved over time

- Explain how you incorporate primary sources into this course. If appropriate, refer to the syllabus

- Why did you decide to incorporate primary sources into this course in this way?

- What challenges do you face in incorporating primary sources into this course?

- Do you incorporate primary sources into all your courses in a similar way? Why or why not?

In this course, does anyone else provide instruction for your students in working with primary sources? Examples: co-instructor, archivist, embedded librarian, teaching assistant

- How does their instruction relate to the rest of the course?

- How do you communicate with them about what they teach, how they teach it, and what the students learn? 


\section{Finding Primary Sources}

Returning to think about your undergraduate teaching in general, how do you find the primary sources that you use in your courses? Examples: Google, databases, own research, library staff

- Do you keep a collection of digital or physical sources that you use for teaching?

- What challenges do you face in finding appropriate sources to use?

How do your students find and access primary sources?

- Do you specify sources which students must use, or do you expect them to locate and select sources themselves?

- If the former, how do you direct students to the correct sources? Do you face any challenges relating to students' abilities to access the sources?

- If the latter, do you teach students how to find primary sources and/or select appropriate sources to work with? Do you face any challenges relating to students' abilities to find and/or select appropriate sources?

\section{Working with Primary Sources}

How do the ways in which you teach with primary sources relate to goals for student learning in your discipline?

- Do you teach your students what a primary source is? If so, how?

- To what extent is it important to you that your students develop information literacy or civic engagement through working with primary sources?

In what formats do your students engage with primary sources? Examples: print editions, digital images on a course management platform, documents in an archive, born-digital material, oral histories

- Do your students visit special collections, archives, or museums, either in class or outside of class? If so, do you or does someone else teach them how to conduct research in these settings?

- Do your students use any digital tools to examine, interact with, or present the sources? Examples: 3D images, zoom and hyperlink features, collaborative annotation platforms, websites, wikis

- To what extent are these formats and tools pedagogically important to you?

- Do you encounter any challenges relating to the formats and tools with which your students engage with primary sources?

\section{Wrapping Up}

Looking toward the future, what challenges or opportunities will instructors encounter in teaching undergraduates with primary sources?

Is there anything else you think I should know? 